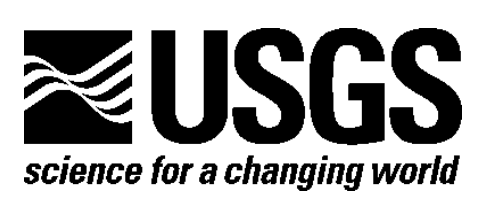

\title{
Accuracy Testing of Electric Groundwater-Level Measurement Tapes
}

By Jim Jelinski, Christopher S. Clayton, and Janice M. Fulford

Open-File Report 2014-1236

U.S. Department of the Interior

U.S. Geological Survey 


\section{U.S. Department of the Interior \\ SALLY JEWELL, Secretary}

\section{U.S. Geological Survey \\ Suzette M. Kimball, Director}

U.S. Geological Survey, Reston, Virginia: 2015

For more information on the USGS-the Federal source for science about the Earth,

its natural and living resources, natural hazards, and the environment-visit

http://www.usgs.gov or call 1-888-ASK-USGS

For an overview of USGS information products, including maps, imagery, and publications, visit http://www.usgs.gov/pubprod

To order this and other USGS information products, visit http://store.usgs.gov

Suggested citation:

Jelinski, J., Clayton, C.S., and Fulford, J.M., 2015, Accuracy testing of electric groundwater-level measurement tapes:

U.S. Geological Survey Open-File Report 2014-1236, 27 p., http://dx.doi.org/10.3133/ofr20141236.

Any use of trade, firm, or product names is for descriptive purposes only and does not imply endorsement by the U.S. Government.

Although this information product, for the most part, is in the public domain, it also may contain copyrighted materials as noted in the text. Permission to reproduce copyrighted items must be secured from the copyright owner.

ISSN 2331-1258 (online) 


\section{Contents}

Abstract

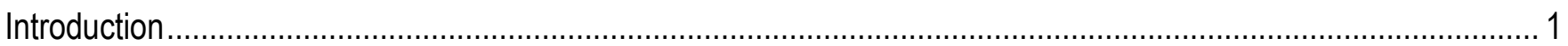

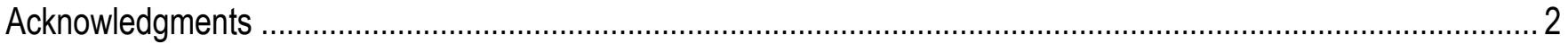

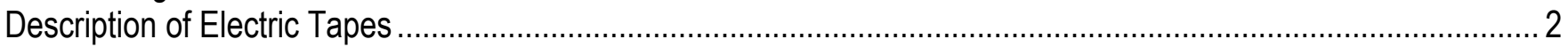

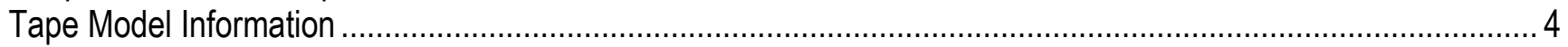

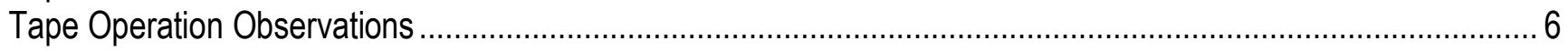

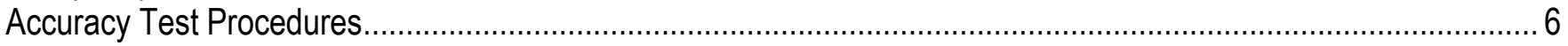

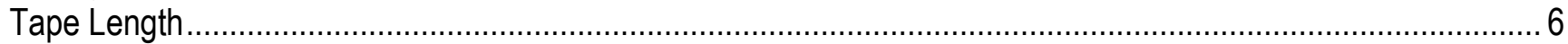

Probe Activation and Volume Displacement ......................................................................................... 8

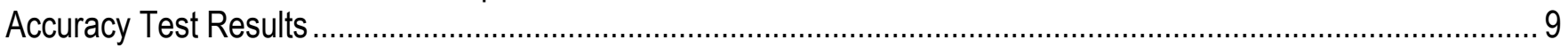

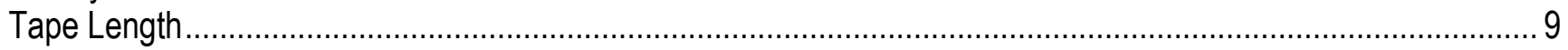

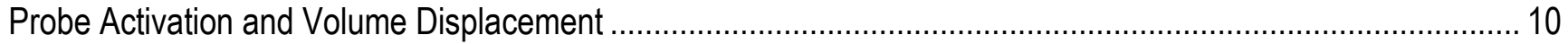

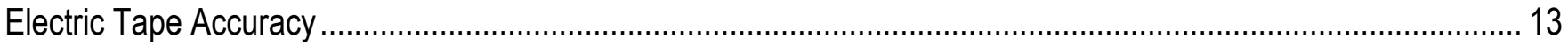

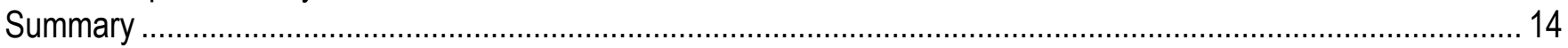

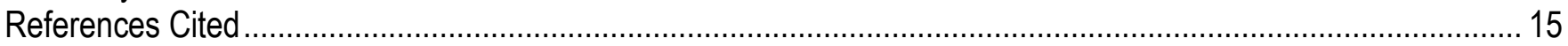

\section{Figures}

[Figures are located at the back of the report]

1. Photos of the electric tapes tested: (Left to right) Durham Geo Water Level Indicator, Geotech ET Water Level Meter, Heron dipper-T Water Level Meter, In-Situ Rugged Water Level Tape 200, Solinst Model 101 P2 Water Level Meter, and Waterline Model 500 Engineering Scale

2. Durham Geo Water Level Indicator: Photo of front of electric tape in upper left, photo of back of electric tape in upper right, closeup of probe in middle photo, and closeup of tape in bottom photo

3. Geotech ET Water Level Meter: Photo of front of electric tape in upper left, photo of back of electric tape in upper right, closeup of probe in middle photo, and closeup of tape in bottom photo

4. Heron dipper-T Water Level Meter: Photo of front of electric tape in upper left, photo of back of electric tape in upper right, closeup of probe in middle photo, and closeup of tape in bottom photo

5. In-Situ Rugged Water Level Tape 200: Photo of front of electric tape in upper left, photo of back of electric tape in upper right, closeup of probe in middle photo, and closeup of tape in bottom photo

6. Solinst Model 101 P2 Water Level Meter: Photo of front of electric tape in upper left, photo of back of electric tape in upper right, closeup of probe in middle photo, and closeup of tape in bottom photo

7. Waterline Model 500 Engineering Scale: Photo of front of electric tape in upper left, photo of back of electric tape in upper right, closeup of probe in middle photo, and closeup of tape in bottom photo

8. The anchor part of the tape-length test apparatus. Upper photo: Two steel tapes in the apparatus. Lower left photo: aligning tape graduations in the apparatus. Lower right photo: Closeup of two tapes in the apparatus, and the blade of the machinist's square used to align them

9. The tensioner part of the tape-length test apparatus. Upper photo: Two steel tapes in the apparatus attached to scales. Lower left photo: Tape graduations being compared using a magnifying glass and the Vernier scale. Lower right photo: Closeup of a steel tape (upper) and an electric tape (lower) on the Vernier scale

10. Three photos of probe-activation test apparatus. Left photo shows the apparatus with the water cup removed. Middle photo shows the apparatus with a tape installed and an inset photo of the hook gages at the water surface. Right photo shows measurement being made between two of the slide-assembly reference surfaces

11. Cumulative error between $100-f t$ electric-tape segment and a steel reference tape over an electric-tape length of $300 \mathrm{ft}$. Electric tapes tested at their in-use tension and steel reference tape at its reference tension

12. Probe-activation zero offset in feet for water with various specific conductance values. Zero offset is positive for probes that activate lower and is negative for probes that activate higher than the zero end of the tape 
13. Closeup photos of the Geotech contact pin just at and after water contact. Note the very small change in water height when the pin makes contact

14. Closeup photos of the Solinst contact pin just before and just after water contact. Note the large change in water height when the pin makes contact

15. The volume of water, in cubic inches, displaced by each probe when lowered to its activation point in water solutions with various specific conductance values

16. Well water-level rise with trend lines based on averaged probe-displacement volumes for six electric-tape models for averaged water sample specific conductance

17. Model average, maximum, and minimum values for the tape-length accuracy for six different models of electric groundwater tape

18. Model average, maximum, and minimum values for the zero offset for six different models of electric groundwater tape

19. Cumulative average differences between electric-tape models and reference measurements over an electrictape length of $300 \mathrm{ft}$ that include checks for tape-length accuracy and for probe zero offset

\section{Tables}

1. Electric well tape features and specifications for the models tested. ................................................... 3

2. Available electric tape lengths for the models tested. ................................................................... 4

3. Measurement statistics for the normalized difference between the electric tape and the steel reference tape for measured 100-ft tape segments. The difference excludes any contribution from the probe.

4. Measurement statistics for probe zero offset test in feet. Probes were set to maximum sensitivity.....

5. Average probe-displacement volumes for six electric-tape models for three water samples of different specific conductance.

6. Calculated well water-level rise based on averaged probe-displacement volumes for six electric-tape models for averaged water sample specific conductances.

7. Model average, maximum, and minimum values measured for zero offset and for the tape-length accuracy. 


\section{Conversion Factors}

Inch/Pound to SI

\begin{tabular}{|c|c|c|}
\hline Multiply & By & To obtain \\
\hline \multicolumn{3}{|c|}{ Length } \\
\hline inch (in.) & 25.4 & millimeter $(\mathrm{mm})$ \\
\hline foot (ft) & 0.3048 & meter $(\mathrm{m})$ \\
\hline \multicolumn{3}{|c|}{ Area } \\
\hline square inch $\left(\mathrm{in}^{2}\right)$ & 6.452 & square centimeter $\left(\mathrm{cm}^{2}\right)$ \\
\hline \multicolumn{3}{|c|}{ Volume } \\
\hline cubic inch $\left(\mathrm{in}^{3}\right)$ & 16.39 & cubic centimeter $\left(\mathrm{cm}^{3}\right)$ \\
\hline \multicolumn{3}{|c|}{ Mass } \\
\hline pound, avoirdupois (lb) & 0.4536 & kilogram (kg) \\
\hline
\end{tabular}

Temperature in degrees Fahrenheit $\left({ }^{\circ} \mathrm{F}\right)$ may be converted to degrees Celsius $\left({ }^{\circ} \mathrm{C}\right)$ as follows:

${ }^{\circ} \mathrm{C}=\left({ }^{\circ} \mathrm{F}-32\right) / 1.8$

Specific conductance is given in microsiemens per centimeter at 25 degrees Celsius $\left(\mu \mathrm{S} / \mathrm{cm}\right.$ at $\left.25^{\circ} \mathrm{C}\right)$. 


\title{
Accuracy Testing of Electric Groundwater-Level Measurement Tapes
}

\author{
By Jim Jelinski, ${ }^{1}$ Christopher S. Clayton, ${ }^{2}$ and Janice M. Fulford ${ }^{3}$
}

\begin{abstract}
Electric tapes are used to measure groundwater levels and to verify the accuracy of pressure transducers installed in wells. Electric tapes are generally assumed to be accurate to \pm 0.01 foot (ft), but little information is available from the manufacturers and no accuracy studies have been conducted to confirm this value. This study measured the accuracy of six popular models of electric groundwater tapes.

The tapes tested include models from Durham Geo, Geotech, Heron, In-Situ, Solinst, and Waterline that are commonly used by the U.S.Geological Survey (USGS). The accuracy tests compared the length of each electric tape to a calibrated-steel reference tape and measured each probe's activation accuracy and displacement volume. The tape-length accuracy combined with the probe-activation accuracy gave the overall measurement accuracy of the tape.

The accuracy tests demonstrated that none of the electric-tape models tested consistently met the suggested USGS accuracy of $\pm 0.01 \mathrm{ft}$. The test data show that the tape models in the study should give a water-level measurement that is accurate to roughly $\pm 0.05 \mathrm{ft}$ per $100 \mathrm{ft}$ without additional calibration. To meet USGS accuracy guidelines, the electric-tape models tested will need to be individually calibrated. Specific conductance also plays a part in tape accuracy. The probes will not work in water with specific conductance values near zero, and the accuracy of one probe was unreliable in very high conductivity water (10,000 microsiemens per centimeter).
\end{abstract}

\section{Introduction}

Electric groundwater-level measurement tapes (electric tapes or e-tapes) are used by the U.S. Geological Survey (USGS) and others to measure groundwater levels in wells. These tapes indicate a water level when an electrical connection is completed by the well water bridging two electrical contacts on the probe. Several models of electric tapes specifically designed to measure groundwater levels are available for purchase. These tapes, when individually calibrated (Freeman and others, 2004, p. 34), are also used to verify the accuracy of pressure transducers installed in groundwater wells. Modern graduated electric tapes are cited as being "commonly accurate to $+/-0.01$ foot" (Cunningham and Schalk, 2011, p. 33). An accuracy of " $0.01 \mathrm{ft}$ or 0.01 percent of depth to water above or below a measuring point, whichever is least restrictive" is suggested for groundwater-level measurements by the

\footnotetext{
${ }^{1}$ U.S. Geological Survey (retired).

${ }^{2}$ U.S. Geological Survey (former employee).

${ }^{3}$ U.S. Geological Survey.
} 
USGS (Freeman and others, 2004, p. 16). However, little information is available from the manufacturers or other independent studies on the accuracy of electric tapes and on whether they meet the suggested USGS accuracy.

Six models of electric tapes, commonly used by the USGS, were purchased and tested: Durham Geo Water Level Indicator, Geotech ET Water Level Meter, Heron dipper-T Water Level Meter, In-Situ Rugged Water Level Tape 200, Solinst Model 101 P2 Water Level Meter, and the Waterline Model 500 Engineering Scale. The tests compared the cumulative-length difference in 100-foot (ft) sections of each tape's graduations to a calibrated steel reference tape and measured each electric tape's activation accuracy and displacement volume in specific conductance solutions with values of near $0 ; 50 ; 1,000$; and 10,000 microsiemens per centimeter at 25 degrees Celsius $(\mu \mathrm{S} / \mathrm{cm})$. The sum of the tape-graduation differences from the standard and the probe-activation (or zero offset) difference from the actual water level gave the overall difference between the tape indication and the true water level, and the overall accuracy of the tape.

This study measured the accuracy of six models of commercially available electric groundwater tapes using a traceable reference. This report describes the methods used to test the electric tapes and the results. It also includes a brief description of the tested tapes and field observations when using the electric tapes, which may affect the overall quality of the data obtained from them.

\section{Acknowledgments}

The research and testing described in this report was funded by the U.S. Geological Survey Office of Groundwater. The authors thank William Cunningham, Rodney Sheets, and the Water Science Field Team for their help and support in this study. Thanks also to Bobby Richards and the Mississippi Water Science Center for their help and insight in field testing the tapes. Gratitude is extended to the reviewers of this report, who made many helpful comments and suggestions.

\section{Description of Electric Tapes}

The six electric-tape models tested in this study are: Durham Geo Water Level Indicator, Geotech ET Water Level Meter, Heron dipper-T Water Level Meter, In Situ Rugged Water Level Tape 200, Solinst Model 101 P2 Water Level Meter, and the Waterline Model 500 Engineering Scale (fig. 1). Three new units of each model were tested, for a total of 18 tapes.

All of the electric-tape models tested are manufactured primarily for use in groundwater wells. An electric tape indicates the water level when an electrical connection is completed by the well water bridging two electrical contacts on the probe. Common features of the tested electric tapes are:

1. A hand-operated reel that includes a stand, a probe holder, and a brake to regulate the rotation of the reel.

2. An indicator module built into the reel hub that includes a light, beeper, test function, sensitivity control and battery, and may include an on/off switch.

3. A "tape" with two electrical conductors, marked in distance graduations, which is spooled onto the reel and connected to the indicator circuit.

4. A probe with a pair of metal contacts that is connected to the conductors at the end of the tape. The contacts are located $1 \mathrm{ft}$ below the 1-ft tape mark. 
The brake on most models is a plastic-tipped screw that bears against the rear flange of the reel. Only the Waterline model uses a brake that is controlled by rotating the knob in the center of the front face of the reel. Table 1 lists some of the features for the various electric-tape models, as well as selected specifications for the electric tapes. Several models have flat-steel tape cores for added strength in addition to the electric conductors. All of the models tested were graduated in decimal feet. Most of the tapes were $300 \mathrm{ft}$ long, the most common length in use, but 100-ft and 500-ft tapes were also tested to check for manufacturing and accuracy differences. Table 2 lists the available lengths for each electrictape model. The Geotech model came with a 20-page operator's manual; all other models came with a single-page information sheet.

Table 1. Electric well tape features and specifications for the models tested.

[in., inches; \%, percent; ft, feet; lbs, pounds; SST, stainless steel; PU, polyurethane; PE, polyethylene; PTFE, polytetrafluoroethylene (Teflon); V, volts]

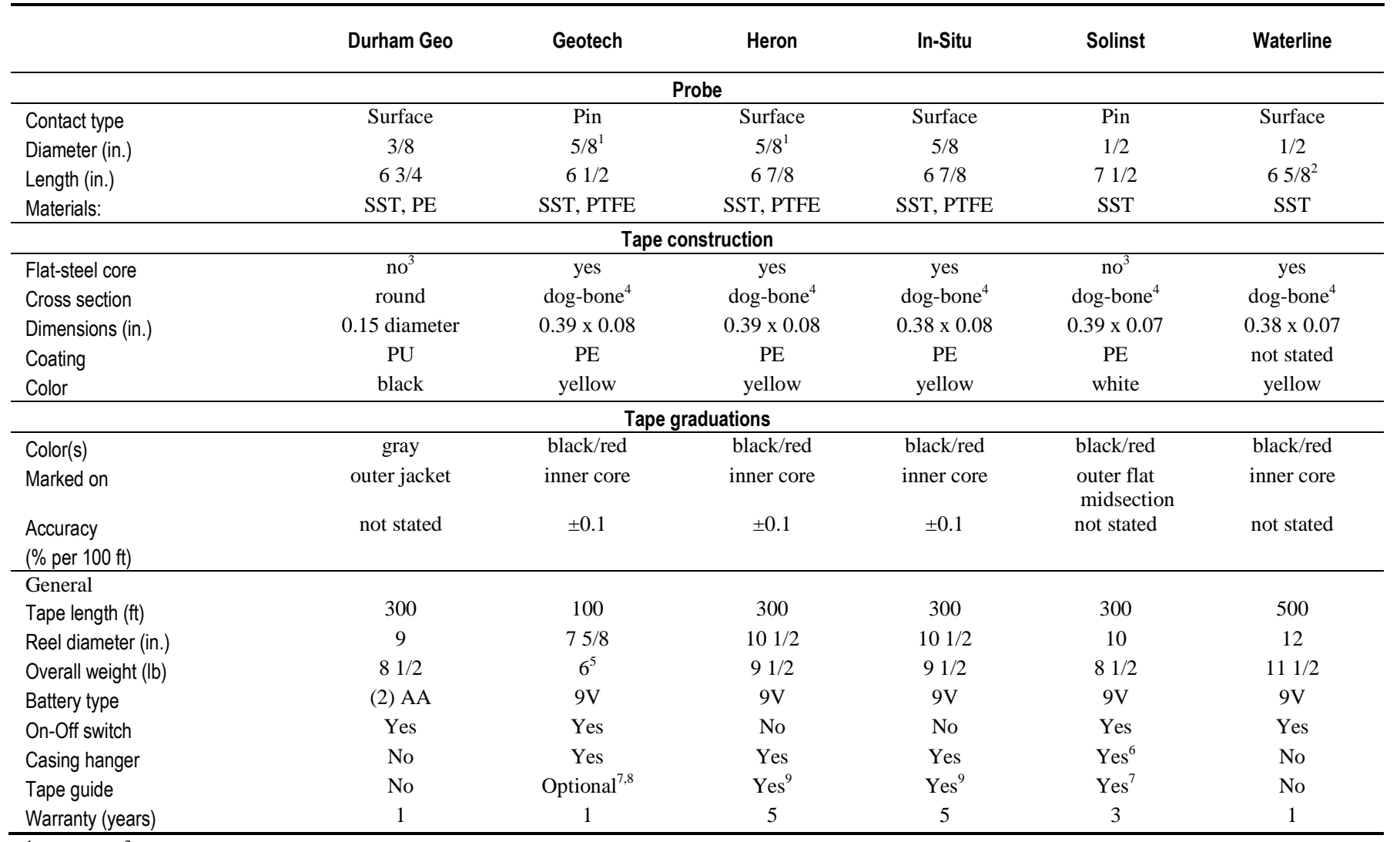

${ }^{1}$ Optional ${ }^{3} / 8$-in. diameter probe of a different design is available (not tested).

${ }^{2}$ Length excludes weight assembly.

${ }^{3}$ Stranded (steel or stainless steel) electrical conductors are also used as strength members.

${ }^{4}$ Dog-bone cross section consists of two circular sides housing the conductors separated by a flat middle, usually containing a flat-steel tape core for strength reinforcement.

${ }^{5}$ The Geotech 300-ft model weighs $14 \mathrm{lbs}$ (information from the operator's manual).

${ }^{6}$ Combined with the tape guide.

${ }^{7}$ Tape guide is a separate piece, placed on the well casing for use.

${ }^{8}$ Casing guide is a separate piece (different from tape guide) standard with the electric tape.

${ }^{9}$ Included with probe holder, attached to the frame. 
Table 2. Available electric tape lengths for the models tested.

[X denotes availability; ft, feet]

\begin{tabular}{|c|c|c|c|c|c|c|}
\hline $\begin{array}{c}\text { Available } \\
\text { lengths } \\
\text { (ft) }\end{array}$ & Durham Geo & Geotech & Heron & In-Situ & Solinst & Waterline \\
\hline 35 & - & - & - & - & - & $\mathrm{X}$ \\
\hline 50 & - & - & $\mathrm{X}$ & - & $\mathrm{X}$ & - \\
\hline 75 & - & - & - & $\mathrm{x}$ & - & $\mathrm{x}$ \\
\hline 100 & $\mathrm{x}$ & $\mathrm{X}$ & $\mathrm{X}$ & $\mathrm{X}$ & $\mathrm{X}$ & - \\
\hline 150 & $\mathrm{x}$ & - & $\mathrm{x}$ & $\mathrm{x}$ & $\mathrm{X}$ & $\mathrm{X}$ \\
\hline 200 & - & $\mathrm{X}$ & $\mathrm{X}^{1}$ & $\mathrm{X}$ & $\mathrm{X}$ & $\mathrm{X}$ \\
\hline 250 & - & - & - & - & $\mathrm{x}$ & - \\
\hline 300 & $\mathrm{x}$ & $\mathrm{x}$ & $\mathrm{X}^{1}$ & $\mathrm{X}$ & $\mathrm{X}$ & $\mathrm{X}$ \\
\hline 500 & $\mathrm{x}$ & $\mathrm{x}$ & $\mathrm{X}^{1,2}$ & $\mathrm{X}^{2}$ & $\mathrm{X}$ & $\mathrm{X}$ \\
\hline 650 & - & - & - & - & $\mathrm{X}$ & - \\
\hline 750 & - & $\mathrm{x}$ & - & $\mathrm{X}^{2}$ & $\mathrm{X}$ & - \\
\hline 800 & - & - & $\mathrm{X}^{1,2}$ & - & - & $\mathrm{x}$ \\
\hline 1,000 & $\mathrm{x}$ & $\mathrm{X}$ & $\mathrm{X}^{1,2}$ & $\mathrm{X}^{2}$ & $\mathrm{X}$ & $\mathrm{X}$ \\
\hline 1,250 & - & - & - & - & $\mathrm{x}$ & - \\
\hline 1,500 & - & - & $\mathrm{X}^{1,2,3}$ & $\mathrm{X}^{2}$ & $\mathrm{x}$ & $\mathrm{x}$ \\
\hline 1,650 & - & - & - & - & $\mathrm{X}$ & - \\
\hline 2,000 & - & - & $\mathrm{X}^{1,2,3}$ & $\mathrm{X}^{2}$ & $\mathrm{X}$ & $\mathrm{X}$ \\
\hline 2,500 & - & - & $\mathrm{X}^{1,2,3}$ & - & $\mathrm{X}^{4}$ & - \\
\hline
\end{tabular}

${ }^{1}$ Available in $100-\mathrm{ft}$ increments to $2,500 \mathrm{ft}$ maximum.

${ }^{2}$ Aluminum-reel flanges for tapes longer than $400 \mathrm{ft}$.

${ }^{3}$ Reel stand is a double-A frame for tapes $1,500 \mathrm{ft}$ long and longer.

${ }^{4}$ Lengths to $6,000 \mathrm{ft}$.

\section{Tape Model Information}

The Durham Geo Water Level Indicator (Durham Geo-Enterprises, 2009) electric tape, commonly known as a Slope Indicator, is shown in figure 2. This electric tape has the smallest diameter probe of the models tested. The electric tape activates when the water covers the polyethylene insulator and completes the electrical circuit between the tip and body of the probe (fig. 2). The tip of the probe has a small cross hole for attaching an additional weight. The "tape" is round coaxial cable with gray graduation marks laser etched into the black polyurethane jacket. The gray-on-black markings are low contrast and are more difficult to read than the higher contrast markings used on the other tapes. The surface of the coaxial cable is noticeably easier to grip than all the other tapes in the test. The steel strands in the cable are used both as electrical conductors and strength members. The Durham Geo reel has aluminum flanges and rotates on bronze bushings. The reel is mounted in a coated tubular steel frame that includes a metal probe holder. The indicator module has a sensitivity switch that includes an "off" position and a separate test button. Some replacement parts are available on the Durham Geo Web site.

The Geotech ET Water Level Meter (Geotech Environmental Equipment, 2008) is shown in figure 3. The tubular stainless-steel probe is attached to the tape below a 2-inch (in.) rubber coupler and can be unscrewed just below the coupler. The electric tape activates when the water closes the electrical circuit between the probe body and the stainless-steel contact pin located between two cross holes in the open tube end of the probe body. The Geotech ET tape has the same construction and appearance as the Heron, In-Situ, and Waterline tapes. The tape is coated in clear polyethylene and is made of insulated wires running along each side of a yellow-coated, flat-steel core-hence, a "dog-bone" cross section 
(table 1). Black numerals are printed at the 1/10-ft marks and the numbers for the "foot" marks are highlighted in red.

The reel uses machined polypropylene flanges that are much thicker (3/8 in.) and heavier than the other plastic reels tested. According to the material provided by the manufacturer, a Geotech ET with a 300-ft length weighs 14 pounds (lbs), which is the heaviest of the 300-ft electric tapes in this test. The indicator module has a sensitivity switch that includes an "off" position, and runs a self-test each time it is turned on. The Geotech frame is made from solid-aluminum round bar and has a welded-on wire casing hanger, a plastic probe holder, and a rubber-cushioned handle (fig. 3). The Geotech includes a separate casing guide that is used to prevent tape abrasion on the top of well casings with diameters in the range of 2 to 4 in. A tape guide (also a separate piece) that prevents the tape from rubbing against the edge of the well casing and being damaged is optional.

The Heron dipper-T Water Level Meter (Heron Instruments Groundwater Monitoring Inc, 2011) is shown in figure 4. The electric tape activates when water covers the Teflon insulator and completes the circuit between the probe tip and the stainless-steel body (fig. 4). Connecting the probe to the tape is a flexible breakaway joint that allows the tape to be recovered if the probe gets jammed in the well.

The Heron tape has the same construction and appearance as the previously described Geotech tape. The Heron reel is molded plastic with thickened edges, and has brass bushings running on a stainless-steel axle. The indicator module includes a loud beeper and a sensitivity control. The tubular steel frame is coated with polyester and includes a cushioned-vinyl carrying handle. The frame has a welded-on wire casing hanger. Near the casing hanger is a molded plastic fitting that is both a probe holder and a tape guide. According to the manufacturer, tapes that are 1,500 ft or longer have a doubleA-frame-style frame.

The In-Situ Rugged Water Level Tape 200 (In-Situ Inc., 2011) is shown in figure 5. The In-Situ Rugged Level Tape 200 electric tapes and reels in the test were nearly identical to the Heron dipper-T electric tapes and reels, except for the reel color, the labeling, and the slightly smaller tape width (0.38 in. compared with 0.39 in.; table 1 ). In-Situ's brochure description of this tape is similar to the description in the Heron brochure for the dipper-T.

The Solinst Model 101 P2 Water Level Meter (Solinst Canada Ltd., 2011) is shown in figure 6. The probe body is a stainless-steel rod, with an oblong cross slot running through the probe at its midpoint (fig. 6). The electric tape activates when water enters the slot and completes the electrical circuit between the body and the contact pin (fig. 6) that protrudes into the cross slot. The Solinst "tape" is unique among the tapes tested in that it has a dog-bone cross section and is made of polyethylene tape running between and insulating two stranded stainless-steel wires that are both electrical conductors and strength members. The Solinst reel is molded plastic with thickened edges. The indicator module is accessed by removing the front face and flange of the reel. The sensitivity switch includes an off position. The frame is made of coated tubular steel. A molded plastic probe carrier is attached to the frame. A separate tape guide is clipped to the frame. This guide is placed on the well casing when used. A hole in the tape guide accepts the front leg of the frame; therefore, it also functions as a casing hanger. According to the manufacturer, a power reel is available for the longer tapes.

The Waterline Model 500 Engineering Scale (Waterline Envirotech Ltd, 2007) is shown in figure 7. The probe body is two sections of stainless steel round tube or round rod separated by hard, dark-gray plastic that appears to be internal-sealing heat-shrink tubing. The electric tape activates when the water level covers the insulator and contacts the upper section, completing the electric circuit. A feature unique to this tested tape is the segmented weight assembly for this probe, with four alternating sections of 0.5-in. outside-diameter rubber hose and stainless-steel rod. The weight sections can be added or removed from the probe. None, some, or all sections can be used as needed. The Waterline 
"tape" has the same construction and appearance as the previously described Geotech "tape." The reel is the largest of the tested reels because it holds the longest tape tested $-500 \mathrm{ft}$. The indicator module includes a rotary switch with "off," "test," "LED," and "buzz" positions. The module is accessed by unscrewing the center brake knob, removing four screws, and lifting away the front-center cover platenot the front flange_ of the reel.

\section{Tape Operation Observations}

An experienced groundwater technician used each tape in the field and made general observations on applicability to various types of wells and on the braking of the reels. None of the electric tapes were usable in the first of the municipal wells visited because the design of the well casing and the angle of the access pipe did not allow clearance for any of the probes to pass through to the water surface. The design of the well casing and access port of the second municipal well visited would only allow the smallest diameter probe (the Durham Geo probe) to pass. A 4-in.-diameter monitoring well was also visited, and a measurement was taken using each of the tapes. The open design of the well allowed all of the tape probes to enter and measurements were obtained without difficulty. During field use, none of the reel brakes could apply the light, steady resistance needed if the reel is placed on the ground and the tape is pulled off in arm-length surges when lowering down a well. The Geotech had the steadiest light braking, but was difficult to adjust for proper operation. All the other brakes either had too much braking variation as the reel turned, or changed setting as the tape was pulled off the reel.

\section{Accuracy Test Procedures}

Two accuracy tests were conducted on the electric tapes: a tape-length test that measured the tape accuracy at each 100-ft graduation marking against a reference tape, and a probe-activation test that measured the zero offset and displacement volume of the probe. Differences with the reference are computed to reflect whether the tape is long (positive difference) or short (negative difference) relative to the reference tape. Short groundwater tapes will measure the groundwater level deeper than the actual water level because more tape will need to be played out to reach the water surface. Similarly, a long groundwater tape will measure the groundwater level shallower than the actual water level because less tape will need to be played out to reach the water surface.

\section{Tape Length}

The procedure for calibrating the tape length described here is based on National Institute of Standards and Technology (NIST) methods (NIST, 1986). The tape length is checked by comparing the electric tape with a NIST-traceable calibrated-steel reference tape. The reference-tape calibration was performed by Lockheed Martin-Stennis Integrated Metrology Center, and the total error of the tape over the $100-\mathrm{ft}$ test section is $0.0009 \mathrm{ft}$ for a $10-\mathrm{lb}$ tension. The procedure used a two-piece apparatus. The apparatus, with an anchor and a tensioner, was designed and built by the USGS Hydrologic Instrumentation Facility (HIF) to accurately compare two tapes side by side. The anchor (fig. 8) is used with a machinist's square to accurately align the graduations of the two tapes. The tensioner (fig. 9) is used to apply and measure the tensile force, or tension, to each tape and to measure the length difference of the test section between the electric tape and the reference tape over a 100-ft segment. The tensioner has a pair of precision digital scales manufactured by CCI Scale Company, Inc., model number HS-30, with a resolution and accuracy of $\pm 0.02 \mathrm{lb}$ to measure the tensile force and a Vernier scale with a 
resolution of $0.0005 \mathrm{ft}$ to measure the length difference. The tensioner has a chain for coarse adjustment of tension and an acme screw for fine adjustment.

The steps used to measure the difference in length between the electric tape and the steel reference tape are:

1. The anchor (fig. 8) and the tensioner (fig. 9) are placed approximately $100 \mathrm{ft}$ apart on a flat concrete floor and weights are placed on the anchor and tensioner to hold them in place.

2. The tapes are stretched out and laid flat, side by side, from the anchor to the tensioner with the graduations facing up. The tapes are oriented so that the reel is near the anchor and the probe (or zero end) of the tape is near the tensioner.

3. The electric tape and the steel reference tape are clamped in the anchor (fig. 8) with the 100-ft mark of the electric tape aligned with the 101-ft mark of the steel reference tape. The tapes are aligned using the edge of the graduation mark closer to the reel and farther away from the probe or zero end of the tape.

4. The electric tape is clamped to a scale in the tensioner (fig. 9) after the first available mark from the probe toward the reel (normally the 2-ft mark) is aligned over the Vernier scale. After the first test section, the 100-ft mark that was aligned in the anchor in the previous section is aligned over the Vernier scale.

5. The steel reference tape is positioned with the 1-ft mark over the Vernier scale and clamped to a scale in the tensioner next to the electric tape.

6. An initial tension of approximately $15 \mathrm{lbs}$ is applied to each tape by using the chain for coarse adjustment and the acme screw for fine adjustment.

7. The tapes are plucked with a vertical motion (just like plucking a chalk line) a few times to get the tapes to settle in to parallel, straight lines.

8. The tension in the steel reference tape is reduced to the reference tension of the tape (10 lbs) that yields the calibrated length of the tape.

9. The tension in the electric tape is reduced to the electric tape "in-use" tension. The in-use tension is the approximate average tension that the 100-ft test section would be subjected to during a water-level measurement in a well. This tension is defined here as equal to the weight of the probe plus the weight of the tape below the midpoint of the 100-ft section being tested.

10. The alignment of the tapes at the anchor end is checked using a magnifier and a machinist's square; adjustments are made, if needed. As in step 3, the edge of each gradation mark closer to the reel is used as the actual measuring point on each tape.

11. At the tensioner end (fig. 9), the difference between the foot marks of the electric tape and the steel reference tape nearest to the tensioner clamp is measured using the Vernier scale. As in step 3, the edge of each gradation mark closer to the reel is used as the actual measuring point on each tape. Because the probe occupies part of the first $100 \mathrm{ft}$ of the electric tape, less than $100 \mathrm{ft}$ of tape (usually $98 \mathrm{ft}$ ) is compared to the reference tape for the first measured tape segment.

12. The positions of the reference tape and electric tape are switched in the apparatus and the segment is measured again using steps 3 through 11.

13. Steps 3 through 12 are repeated until four measurements (two measurements in each of two positions) are made over the segment.

14. The electric tape is moved to align the next higher 100-ft marking to the steel reference tape's 101-ft marking and steps 3 through 13 are repeated until the entire length or $300 \mathrm{ft}$ of the electric tape has been compared to the steel reference tape. 
The four measurements made for a particular segment are averaged to determine the accuracy of that segment of tape. The scatter (variability) in the measurements gives an indication of the repeatability (precision) of the measurements.

\section{Probe Activation and Volume Displacement}

The probe-activation and volume-displacement tests measure the activation accuracy of the probe and the displacement volume of the probe in water when activated. All electric-tape probes are built with a contact that completes the electrical circuit located $1 \mathrm{ft}$ below the 1-ft tape mark. However, surface tension and specific conductance of the water, and probe materials and shape, can affect the point at which the electrical circuit is completed. This can result in the probe activating either higher or lower than the true zero location. The activation accuracy (or zero offset) is the difference between the water level at activation relative to the 1-ft mark on the tape and a measured 1-ft distance by use of a calibrated hook gage. The probe displacement volume is the volume of water displaced by the probe when the probe is lowered into the water to its activation point. It can be used to calculate the waterlevel rise in a well due to the probe during a measurement, which can be an issue in small diameter wells.

The apparatus for the probe-activation test was designed and built by HIF and is shown in figure 9. The apparatus has three vertically adjustable slide assemblies (fig. 10) — the middle slide holds the tape, and the two side slides hold hook gages that are used to measure the activation accuracy and the displacement volume (inset in middle photo, fig. 10). The flat measurement surface of the hook-gage slide assembly (right photo, fig. 10) is $1 \mathrm{ft}$ above the upturned points of the hook gage.

The steps to measure the activation accuracy and displacement volume are:

1. The test cup with a known radius is filled with water of a known specific conductance and set in the test apparatus.

2. An electric tape is attached to the middle vertically adjustable slide so that the 1 -ft tape mark is flush with the top of the flat measurement surface. The tape slide is positioned and locked so that the probe is just above the water in the cup.

3. The hook gages are brought up until the hooks begin to dimple the water surface and are locked in position.

4. The electric tape is lowered into the test cup until the tape activates and the tape slide is locked in position. The resulting water level is the activation level.

5. One hook gage is raised to the new water level, the activation level, and locked in position.

6. The distance between the tape slide measurement surface (at the 1- $\mathrm{ft}$ mark on the tape) and the measurement surface of the hook gage set to the activation level is carefully measured with a dial caliper having a resolution of 0.001 in (fig. 10). This is the probe-activation accuracy (or the electric-tape zero offset).

7. The distance between the two hook gages' measurement surfaces - one at the undisturbed water level and the other at the activation water level - is carefully measured with a dial caliper. This measurement is the increase in water level (h) due to the probe displacing water and is used with the cup surface area (Area $=\pi *$ radius 2 ) to calculate the volume of water displaced by the probe $($ Volume $=$ Area $*$ h).

For each known specific conductance, the measurement was repeated five times for each tape and averaged. Water with four different specific conductances was used: deionized water; 50; 1,000; and 
$10,000 \mu \mathrm{S} / \mathrm{cm}$. Except for the very low specific conductance of the deionized water $(<5 \mu \mathrm{S} / \mathrm{cm})$, test solutions were made using deionized water and conductance standards. Prior to each test, a calibrated specific conductance meter was used to check the test solution. If the specific conductance was higher than specified, deionized water was carefully added to bring the test solution to the proper specific conductance value.

During preliminary testing, adjustments to the sensitivity setting of particular tapes substantially changed the activation height. In order to obtain a consistent test, all tapes were tested at maximum sensitivity.

\section{Accuracy Test Results}

The following sections describe the results of the tape-length, probe-activation, and volumedisplacement tests. Graphs and tables giving simple statistics are included and are used to compare the results between each set of tapes and among all tapes. All of the length tests were conducted at the HIF Hydraulics Laboratory on a large, dry, flat area of concrete floor. The average temperature was $28.7^{\circ} \mathrm{C}$. The maximum and minimum temperatures during testing were $29.6{ }^{\circ} \mathrm{C}$ and $27.7^{\circ} \mathrm{C}$, respectively, extending over several days. Therefore, the maximum possible temperature difference during calibration was $1.9^{\circ} \mathrm{C}$. The steel-tape coefficient of expansion is $0.0000116 \mathrm{ft}$ per degree Celsius. This means the maximum possible length change over a 100-ft section was $0.0022 \mathrm{ft}$. Given that the tapes were allowed to equalize to the ambient temperature over several hours, the actual temperature difference between the tapes was negligible and no temperature correction was performed on the data.

\section{Tape Length}

The measured differences between an electric tape and the steel reference tape were summed to give the cumulative difference (error) at 100-ft, 200-ft, and 300-ft tape markings. The measured difference is the average of four repeated measurements, and are positive when the electric tape is longer than the steel reference tape (which would measure a shallower water level) and are negative when the electric tape is shorter than the steel reference tape (which would measure a deeper water level). Figure 11 shows the cumulated measured differences for each electric tape. The Geotech tapes were $100 \mathrm{ft}$ long and had only one comparison measurement per tape. The Waterline 500 tapes' in-use tension did not include the weight assembly sections and only $300 \mathrm{ft}$ of the 500 -ft tapes were measured.

Most (14 out of 18) of the electric tapes had measured differences that were negative (shorter than the reference tape), meaning that most of the electric tapes would measure a water level deeper than the actual level. Two of the Solinst tapes had measured accuracies of less than $0.01 \mathrm{ft}$ over their entire 300-ft length. The third Solinst tape had a positive measured difference (longer than the reference tape) over each 100-ft tape segment. During testing, it was observed that Solinst tapes stretched the most out of all the tapes tested. Solinst tapes are marked to be accurate while stretched under well measurement tensions. None of the other tapes had an unadjusted accuracy in any of the segments, or cumulatively, of $\leq 0.01 \mathrm{ft}$.

Table 3 contains the average, standard deviation, maximum, and minimum normalized differences compiled for each model, using the replicated measurements from the length-accuracy test data. The differences between the electric tape and the steel tape were normalized to give a difference per $100 \mathrm{ft}$ by dividing the difference between the electric tape and the steel reference tape by the actual test section length in feet, and multiplying the result by 100. The Waterline 500 tapes had the largest average difference $(-0.0488 \mathrm{ft})$, but had less variability (standard deviation) from tape to tape $(0.0028 \mathrm{ft})$ than all but one model. Although the Durham Geo tapes had the smallest average difference 
$(-0.0001 \mathrm{ft})$, they also had the largest variability from tape to tape $(0.0226 \mathrm{ft})$. The Geotech tapes had the least variability from tape to tape $(0.0011 \mathrm{ft})$, but also had a large average difference $(-0.0397 \mathrm{ft})$.

The electric-tape models using the same, or similar, steel-core type tapes (In-Situ Rugged Tape, Geotech, Heron dipper-T, and Waterline 500) were expected to have a similar range of differences and variability between the tapes. The average difference for these models ranged from -0.0001 to $-0.0488 \mathrm{ft}$ and the standard deviations ranged from 0.0011 to $0.0047 \mathrm{ft}$; these results may indicate either lot-to-lot variability or differences in acceptance testing by the manufacturers of the tapes used in these models. The Heron and In-Situ models tested appear to be the same, except for labeling differences, and have similar statistics and length differences.

Table 3. Measurement statistics for the normalized difference between the electric tape and the steel reference tape for measured 100-foot (ft) tape segments. The difference excludes any contribution from the probe.

\begin{tabular}{lcccc}
\hline \multicolumn{1}{c}{ Model } & $\begin{array}{c}\text { Maximum } \\
(\mathrm{ft})\end{array}$ & $\begin{array}{c}\text { Average } \\
(\mathrm{ft})\end{array}$ & $\begin{array}{c}\text { Standard deviation } \\
(\mathrm{ft})\end{array}$ & $\begin{array}{c}\text { Minimum } \\
(\mathrm{ft})\end{array}$ \\
\hline Durham Geo & 0.0376 & -0.0001 & 0.0229 & -0.0209 \\
Geotech & -0.0383 & -0.0397 & 0.0011 & -0.0405 \\
Heron & -0.0203 & -0.0263 & 0.0033 & -0.0310 \\
In-Situ & -0.0218 & -0.0299 & 0.0047 & -0.0369 \\
Solinst & 0.0365 & 0.0065 & 0.0136 & -0.0048 \\
Waterline & -0.0453 & -0.0488 & 0.0028 & -0.0528 \\
\hline
\end{tabular}

\section{Probe Activation and Volume Displacement}

There are two sets of measurements from the probe-activation test; the activation accuracy (or zero offset), and the probe-displacement volume. None of the electric tapes activated reliably or consistently at very low (less than $5 \mu \mathrm{S} / \mathrm{cm}$ ) specific conductance because the tapes rely on water conductivity to operate. Therefore, no results are presented for the very low specific conductance of the deionized water.

The measured probe zero offset is plotted in figure 12. The zero offset for a tape is the average of five repeated measurements. A positive offset means that the electric tape activates before the zero end of the tape meets the water and increases the length of the tape and causes a shallower than actual measurement. A negative offset means that the electric tape activates after the zero end of the tape meets the water and decreases the effective length of the tape and causes a deeper than actual measurement.

The Durham Geo probe was impractical to use in $10,000 \mu \mathrm{S} / \mathrm{cm}$ water when it was set to maximum sensitivity; no repeatable measurement could be obtained. Reducing the sensitivity improved operation for the $10,000-\mu \mathrm{S} / \mathrm{cm}$ water, but also changed the zero offset from -0.036 to $0.025 \mathrm{ft}$, depending on the sensitivity setting. Therefore, results are shown only for the $50-$ and $1,000-\mu \mathrm{S} / \mathrm{cm}$ solutions for this probe.

The Geotech probe had the smallest average zero offsets, from -0.0023 to $-0.0040 \mathrm{ft}$, and the Solinst 101 had the largest zero offsets, from -0.0093 to -0.0139 (fig. 12). Both of these probes use a pointed contact pin between two holes in the probe body. The Geotech probe had a good, repeatable response to water contact due to the probe pin design. The probe did not cause substantial water-level rise (fig. 13). For the Solinst 101 probe, the water between the contact pin and the cross slot tended to wick up onto the contact pin before the actual water surface met the pin (fig. 14). Most probes, except for the Waterline 500, did not show any obvious trends with increasing specific conductance (fig. 12). The zero offset for the Waterline 500 probe tended to decrease with increasing specific conductance. 
This behavior is a result of interaction between the water and the sharp edge and flat "shelf" at the upper edge of the insulator between the two metal contacts (fig. 7). The Durham Geo probe had the largest variation from measurement to measurement because of the inconsistent interaction of water with the vshaped groove between the insulator and the probe body (fig. 2). Because the Heron dipper-T and In-Situ Rugged probes are the same design, they had similar zero offsets. For these probes, the water rising up the probe tends to "bend down" around the Teflon insulator and then "bend up" onto the metal probe body (figs. 4 and 5). Table 4 lists by model the average, standard deviation, maximum, and minimum of the replicated measurements for the zero offsets.

The results of the probe-displacement volume measurement are shown in figure 15. For the Waterline probe, the displacement is that of the probe only; the weight assembly is not attached. The Waterline weight displaces approximately 0.63 cubic inch $\left(\mathrm{in}^{3}\right)$ for each rubber hose and stainless-steel rod section. This volume is dependent on how far the pieces are pushed together.

Changes in specific conductance did not greatly affect the volume displaced by the probes. The Geotech probe had the smallest ( 0.0192 to $\left.0.0346 \mathrm{in}^{3}\right)$ and the Solinst had the largest (0.5110 to $0.6639 \mathrm{in}^{3}$ ) displacement volumes. Because the Heron dipper-T and In-Situ Rugged probes are the same design, they displaced similar amounts of water from 0.1578 to $0.2040 \mathrm{in}^{3}$. The Durham Geo probes displaced from 0.1260 to $0.1655 \mathrm{in}^{3}$ and the Waterline 500, without the weight sections, displaced from 0.2752 to $0.3156 \mathrm{in}^{3}$. Adding weight sections to the Waterline probe increased the displacement by approximately 0.63 in $^{3}$ per section and can vary depending on how far the sections are pushed together. Table 5 lists the average displacement volume measured for each tape model in water of three different specific conductance values. The average value for the measurements over all the water samples is also listed in the table.

Table 6 shows the calculated water-level rise in pipes with inside diameters ranging from 0.82 to $6.07 \mathrm{in}$., equivalent to schedule 40 pipe diameters ranging from $3 / 4$ to $6 \mathrm{in}$. The water rise represents the average probe displacement for the three specific conductance values. Values for the Waterline tape are shown with and without all weight sections attached. These data are also plotted with trend lines in figure 16. 
Table 4. Measurement statistics for probe zero offset test in feet.

[Probes were set to maximum sensitivity. Zero offset is positive for probes that activate lower and is negative for probes that activate higher than the zero end of the tape; $\mathrm{ft}$, feet; $\mu \mathrm{S} / \mathrm{cm}$, microsiemens per centimeter; --, measurements at $10,000 \mu \mathrm{S} / \mathrm{cm}$ were not repeatable]

\begin{tabular}{|c|c|c|c|c|}
\hline Model & $\begin{array}{l}\text { Maximum } \\
(\mathrm{ft})\end{array}$ & $\begin{array}{c}\text { Average } \\
\text { (ft) }\end{array}$ & Standard deviation (ft) & $\begin{array}{c}\text { Minimum } \\
\text { (ft) }\end{array}$ \\
\hline & \multicolumn{4}{|c|}{ Specific conductance $50 \mu \mathrm{S} / \mathrm{cm}$} \\
\hline Durham Geo & -0.0016 & -0.0035 & 0.0019 & -0.0055 \\
\hline Geotech & -0.0023 & -0.0026 & 0.0007 & -0.030 \\
\hline Heron & 0.0061 & 0.0040 & 0.0011 & 0.0010 \\
\hline In-Situ & 0.0084 & 0.0065 & 0.0021 & 0.0046 \\
\hline Solinst & -0.0093 & -0.0103 & 0.0013 & -0.0123 \\
\hline \multirow[t]{2}{*}{ Waterline } & 0.0104 & 0.0075 & 0.0022 & 0.0038 \\
\hline & \multicolumn{4}{|c|}{ Specific conductance $1,000 \mu \mathrm{S} / \mathrm{cm}$} \\
\hline Durham Geo & -0.0020 & -0.0079 & 0.0047 & -0.0121 \\
\hline Geotech & -0.0024 & -0.0030 & 0.0006 & -0.0034 \\
\hline Heron & 0.0057 & 0.0042 & 0.0026 & 0.0023 \\
\hline In-Situ & 0.0089 & 0.0071 & 0.0022 & 0.0047 \\
\hline Solinst & -0.0107 & -0.0119 & 0.0013 & -0.0128 \\
\hline \multirow[t]{2}{*}{ Waterline } & 0.0078 & 0.0043 & 0.0029 & 0.0003 \\
\hline & \multicolumn{4}{|c|}{ Specific conductance $10,000 \mu \mathrm{S} / \mathrm{cm}$} \\
\hline Durham Geo ${ }^{1}$ & -- & -- & -- & -- \\
\hline Geotech & -0.0024 & -0.0032 & 0.0007 & -0.0040 \\
\hline Heron & 0.0058 & 0.0040 & 0.0010 & 0.0017 \\
\hline In-Situ & 0.0082 & 0.0055 & 0.0010 & 0.0038 \\
\hline Solinst & -0.0110 & -0.0129 & 0.0013 & -0.0139 \\
\hline Waterline & 0.0043 & 0.0015 & 0.0071 & 0.0029 \\
\hline
\end{tabular}

${ }^{1}$ Durham Geo probe-activation measurements at $10,000 \mu \mathrm{S} / \mathrm{cm}$ were not repeatable.

Table 5. Average probe-displacement volumes for six electric-tape models for three water samples of different specific conductance.

$[\mu \mathrm{S} / \mathrm{cm}$, microsiemens per centimeter; --, measurements at $10,000 \mu \mathrm{S} / \mathrm{cm}$ were not repeatable]

\begin{tabular}{|c|c|c|c|c|}
\hline \multirow[t]{2}{*}{ Model } & \multicolumn{4}{|c|}{ Probe displacement volume in cubic inches } \\
\hline & $50 \mu S / c m$ & $1,000 \mu \mathrm{S} / \mathrm{cm}$ & $10,000 \mu \mathrm{S} / \mathrm{cm}$ & All samples \\
\hline Durham $\mathrm{Geo}^{1}$ & 0.1485 & 0.1485 & -- & 0.1485 \\
\hline Geotech & 0.0263 & 0.0237 & 0.0227 & 0.0242 \\
\hline Heron & 0.1866 & 0.1777 & 0.1796 & 0.1813 \\
\hline In-Situ & 0.1860 & 0.1854 & 0.1668 & 0.1794 \\
\hline Solinst & 0.6369 & 0.6318 & 0.5421 & 0.6036 \\
\hline Waterline without weight & 0.3130 & 0.2912 & 0.2874 & 0.2972 \\
\hline Waterline with weight & 2.8330 & 2.8112 & 2.8074 & 2.8172 \\
\hline
\end{tabular}

${ }^{1}$ Durham Geo probe-activation measurements at $10,000 \mu \mathrm{S} / \mathrm{cm}$ were not repeatable. 
Table 6. Calculated well water-level rise based on averaged probe-displacement volumes for six electric-tape models for averaged water sample specific conductance.

[Diameters (dia) shown are the nominal inside diameter for 3/4-in., 1-in., 2-in., 4-in., and 6-in. schedule 40 pipe]

\begin{tabular}{|c|c|c|c|c|c|}
\hline \multirow[t]{2}{*}{ Model } & \multicolumn{4}{|c|}{ Well water level rise in feet } & \multirow[b]{2}{*}{6.07 -in. dia } \\
\hline & 0.82 -in. dia & 1.05-in. dia & 2.07-in. dia & 4.03-in. dia & \\
\hline Durham Geo & 0.0209 & 0.0129 & 0.0033 & 0.0009 & 0.0004 \\
\hline Geotech & 0.0038 & 0.0023 & 0.0006 & 0.0002 & 0.0001 \\
\hline In-Situ & 0.0280 & 0.0173 & 0.0045 & 0.0012 & 0.0005 \\
\hline Solinst & 0.0944 & 0.0583 & 0.0150 & 0.0040 & 0.0017 \\
\hline Waterline without weight & 0.0462 & 0.0285 & 0.0073 & 0.0019 & 0.0009 \\
\hline
\end{tabular}

\section{Electric Tape Accuracy}

The overall electric-tape accuracy is the sum of the activation accuracy (or zero offset) and the tape-length accuracy. Table 7 lists the model average, maximum, and minimum values for the zero offset and the tape-length accuracy. For each tape, the zero offsets measured for water samples of three conductance levels were averaged to give a single value. Similarly, the differences with the steel reference tape for each 100-ft segment were averaged to give a single value for difference per $100 \mathrm{ft}$ for each tape. The model average is the average of the tapes of the same model. The model maximum and minimum are the measured values for the unit of that model with either the maximum or minimum value.

Figures 17 and 18, respectively, show the average, maximum, and minimum values for the tapelength accuracy, and the average, maximum, and minimum values for the zero offset plotted, for each of the models tested. The probe zero offset is significantly more accurate than the tape-length accuracy per 100-ft segment. The values plotted for the Heron dipper-T and the In-Situ Rugged Tape are similar in range and average for both tape-length accuracy and zero offset. The zero offset for most of the probes are within \pm 0.01 - $\mathrm{ft}$ accuracy. The cumulative average differences between the particular tape model and reference measurements are plotted with the accuracy of $\pm 0.01 \mathrm{ft}$ in figure 19 . The \pm 0.01 - $\mathrm{ft}$ accuracy limit is actually plotted at $\pm 0.0144 \mathrm{ft}$ to account for rounding errors and the limitations imposed by using only two significant figures. Mathematically, $0.0144 \mathrm{ft}$ will round down to $0.01 \mathrm{ft}$ while $0.0145 \mathrm{ft}$ will round up to $0.02 \mathrm{ft}$. Most of the models are not within $\pm 0.01-\mathrm{ft}$ accuracy and most models tend to have short effective lengths; short tapes will measure water levels as deeper than the actual water levels. Based on these tests, the electric-tape models do not have an accuracy of $\pm 0.01 \mathrm{ft}$. The tapes tested should give a measurement that is generally accurate $\pm 0.05 \mathrm{ft}$ per $100 \mathrm{ft}$ without additional calibration. To meet the USGS accuracy suggestion of $\pm 0.01 \mathrm{ft}$, the electric-tape models tested would need to be individually calibrated, and a correction factor or table devised and used, as described by Cunningham and Schalk (2011). If highly accurate measurements are needed, then the electric-tape probeactivation/zero offset should also be checked and corrected for using a sample of water drawn from the well being measured. 
Table 7. Model average, maximum, and minimum values measured for zero offset and for the tape-length accuracy. Three tapes were tested for each model. Probe offset are average values for tests in water of 50; 1,000; and 10,000 microsiemens per centimeter $(\mu \mathrm{S} / \mathrm{cm})$, and tape-length accuracy are average values for three $100-\mathrm{ft}$ tape segments.

\begin{tabular}{|c|c|c|c|c|c|c|}
\hline \multirow[b]{2}{*}{ Model } & \multicolumn{3}{|c|}{ Probe zero offset in feet } & \multicolumn{3}{|c|}{ Tape-length accuracy in feet } \\
\hline & Average & Maximum & Minimum & Average & Maximum & Minimum \\
\hline Durham Geo & -0.0057 & -0.0018 & -0.0088 & -0.0001 & 0.0376 & -0.0209 \\
\hline Geotech & -0.0029 & -0.0024 & -0.0035 & -0.0397 & -0.0383 & -0.0405 \\
\hline Heron & 0.0041 & 0.0058 & 0.0017 & -0.0263 & -0.0203 & -0.0310 \\
\hline In-Situ & 0.0064 & 0.0085 & 0.0044 & -0.0299 & -0.0218 & -0.0369 \\
\hline Solinst & -0.0117 & -0.0103 & -0.0130 & 0.0065 & 0.0365 & -0.0048 \\
\hline Waterline & 0.0044 & 0.0075 & 0.0002 & -0.0488 & -0.0453 & -0.0528 \\
\hline
\end{tabular}

\section{Summary}

The sum of the tape-graduation differences from the standard and the probe-activation (or zero offset) difference from the actual water level gave the overall difference between the tape indication and the true water level, and the overall accuracy of the tape. None of the electric-tape models had all sample tapes meet the $\pm 0.01-\mathrm{ft}$ USGS accuracy suggestion during the tape-length testing. Most of the probes by themselves, however, did meet $\pm 0.01-\mathrm{ft}$ accuracy. Any of the tapes in the study should give a measurement that is accurate to roughly $\pm 0.05 \mathrm{ft}$ per $100 \mathrm{ft}$ without individual calibration. However, if calibrated against an in-calibration steel tape and used with the calibration correction factor or table, most of the tapes would meet \pm 0.01 - $\mathrm{ft}$ accuracy. A few of the tapes would also require a probe zero offset calibration and correction in addition to the tape correction in order to meet \pm 0.01 -ft accuracy. If the specific conductance of the well water is near zero, none of the electric tapes will work, as they all depend on conductive water to complete the electrical circuit. If the specific conductance is near or greater than $10,000 \mu \mathrm{S} / \mathrm{cm}$, the electric tape probe should be checked to ensure that it will operate properly with water from that well.

The visually identical "tapes" used in the Geotech, Heron, In-Situ, and Waterline electric tapes all measured shorter than the steel reference tape, outside the limits of \pm 0.01 - $\mathrm{ft}$ accuracy. These tapes were, however, consistent along the length of each tape and usually consistent between the different units in the test from each manufacturer. Two Solinst tapes met the USGS accuracy statement over their full length. Probes-activation tests measured an overall zero offset range of $+/-0.014 \mathrm{ft}$ in test solutions of 50; 1,000; and 10,000 $\mu \mathrm{S} / \mathrm{cm}$ for the models tested. One of the tapes, the Durham Geo, experienced issues in very high conductivity water $(10,000 \mu \mathrm{S} / \mathrm{cm})$ and could not accurately measure water level at that conductivity.

Any of the electric tapes can be checked against a calibrated steel tape, the variation from the steel tape noted, and a correction factor or table can be devised. The greater accuracy desired, the more attention that must be paid to calibration conditions, such as tape tensions, temperatures, and smoothness of the supporting surface. Overall, most of the tapes were shorter than their marked length. As a result, most of the tapes, if uncorrected, would measure a deeper than actual well water level. 


\section{References Cited}

Cunningham, W.L., and Schalk, C.W., comps., 2011, Groundwater technical procedures of the U.S. Geological Survey: U.S. Geological Survey Techniques and Methods, book 1, chap. A1, 151 p. Durham Geo-Enterprises, Inc. [2009], Water level indicators: Durham Geo-Enterprises, Inc. Web page, accessed October 19, 2011, at http://durhamgeo.com/Ground-Water/water-level-indicator.html.

Freeman, L.A., Carpenter, M.C., Rosenberry, D.O., Rousseau, J.P., Unger, R. and McLean, J.S., 2004, Use of submersible pressure transducers in water-resources investigations: U.S. Geological Survey: Techniques of Water-Resources Investigations, book 8, chap. A3, 52 p. Geotech Environmental Equipment, Inc. [2008], Water Level Meters: Geotech Environmental Equipment, Inc. Web page, accessed October 19, 2011, at http://www.geotechenv.com/water_level_meters.html.

Heron Instruments Groundwater Monitoring Inc [2011], Dipper-t Water Level Meter: Heron Instruments Groundwater Monitoring Inc Web page, accessed October 19, 2011, at http://www.heroninstruments.com/dipper-t-water-level-meter.aspx.

In-Situ Inc. [2011], Rugged Water Level Tape 200: In-Situ Inc. Web page, accessed August 15, 2012, at http://www.in-situ.com/products/water-level/level-tapes/level-tape-200.

National Institute of Standards and Technology, Standard Operating Procedure Number 12: Recommended Standard Operations Procedure for Calibration of Steel Tapes, Tape-to-Tape Method, 1986.

Solinst Canada Ltd. [2011], Model 101 Water Level Meters: Solinst Canada Ltd. Web page, accessed October 19, 2011, at http://www.solinst.com/Prod/101/101d3.html.

Waterline Envirotech Ltd [2007], Products: Waterline Envirotech Ltd Web page, accessed on October 17, 2012, at http://waterlineusa.com/products.htm. 


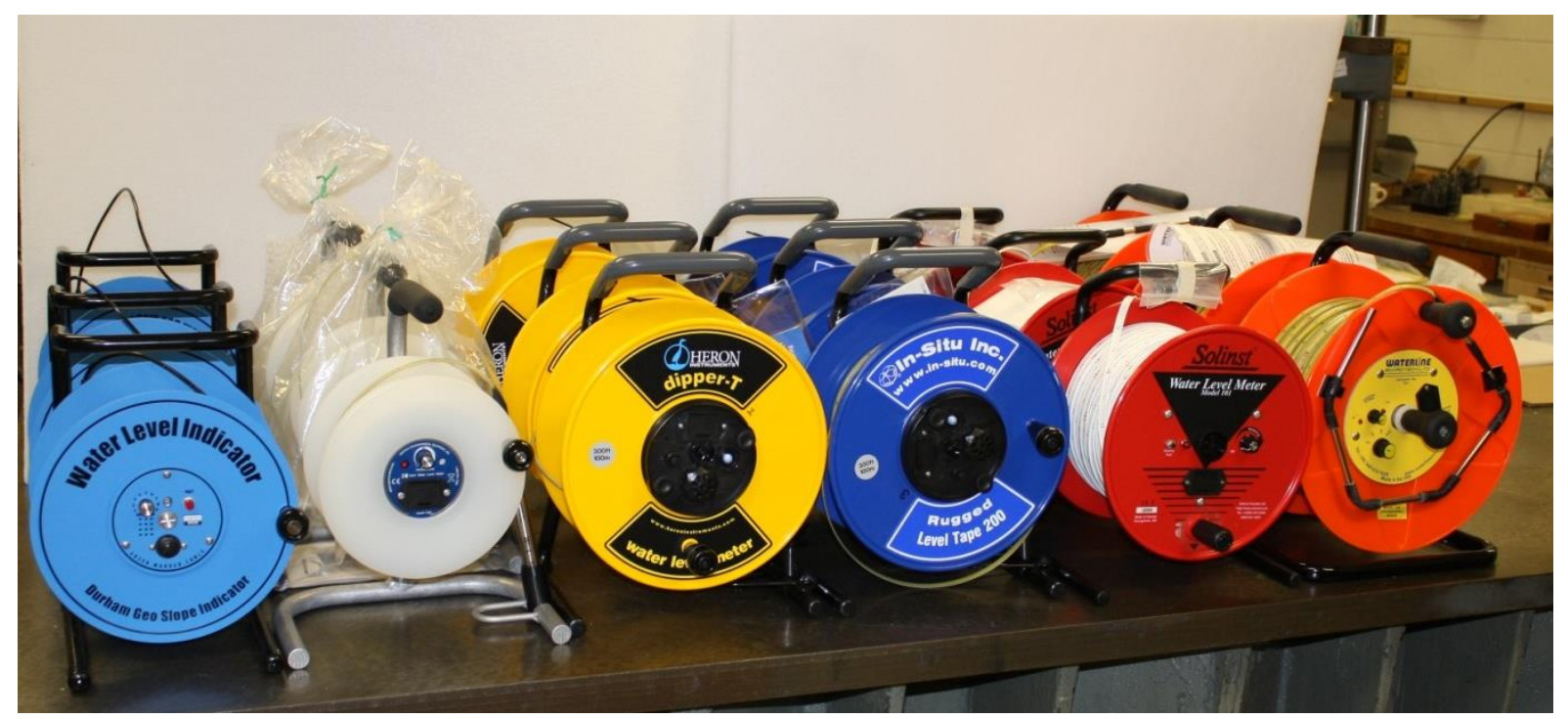

Figure 1. Photos of the electric tapes tested: (Left to right) Durham Geo Water Level Indicator, Geotech ET Water Level Meter, Heron dipper-T Water Level Meter, In-Situ Rugged Water Level Tape 200, Solinst Model 101 P2 Water Level Meter, and Waterline Model 500 Engineering Scale. 


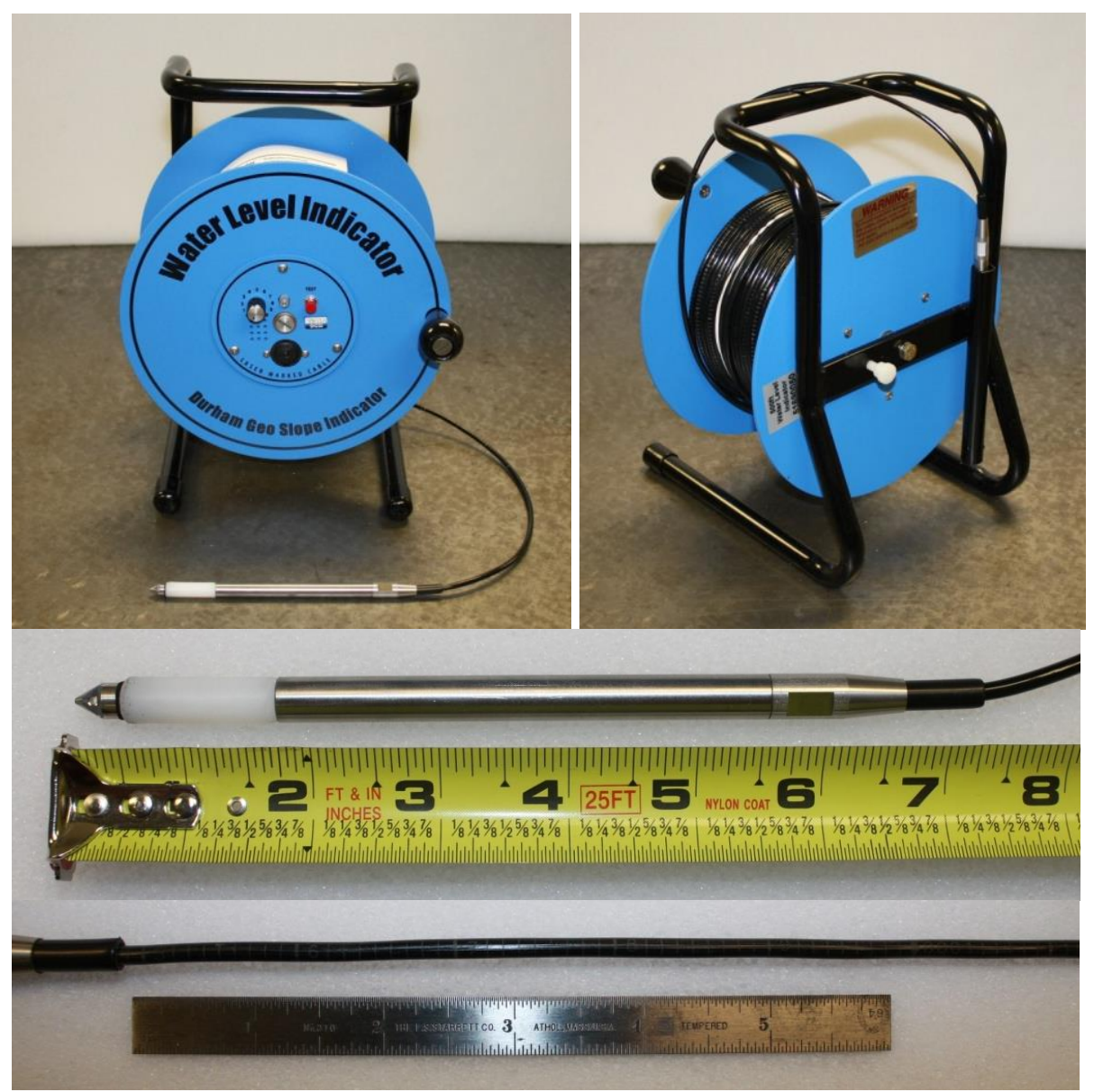

Figure 2. Durham Geo Water Level Indicator: Photo of front of electric tape in upper left, photo of back of electric tape in upper right, closeup of probe in middle photo, and closeup of tape in bottom photo. 

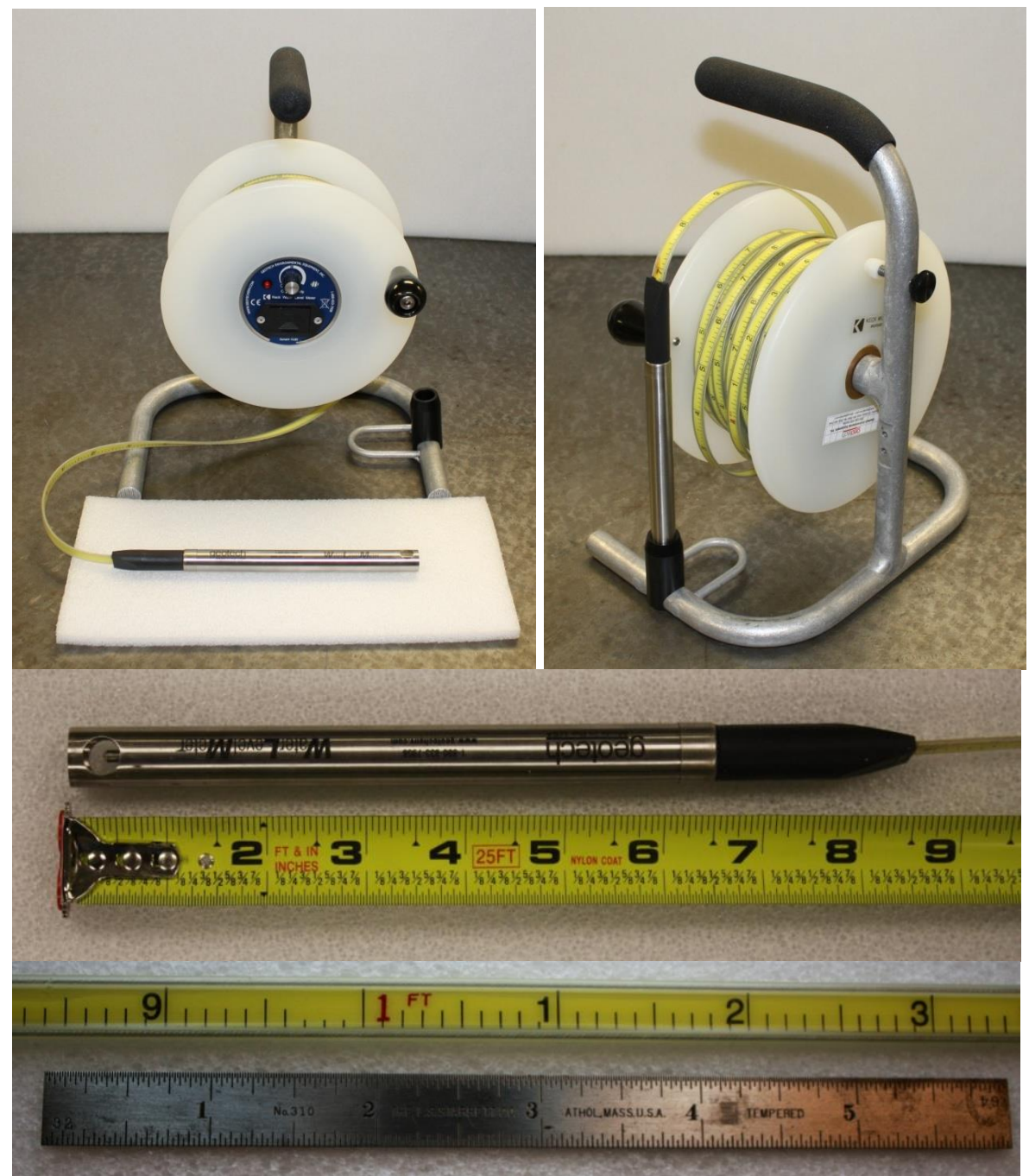

Figure 3. Geotech ET Water Level Meter: Photo of front of electric tape in upper left, photo of back of electric tape in upper right, closeup of probe in middle photo, and closeup of tape in bottom photo. 


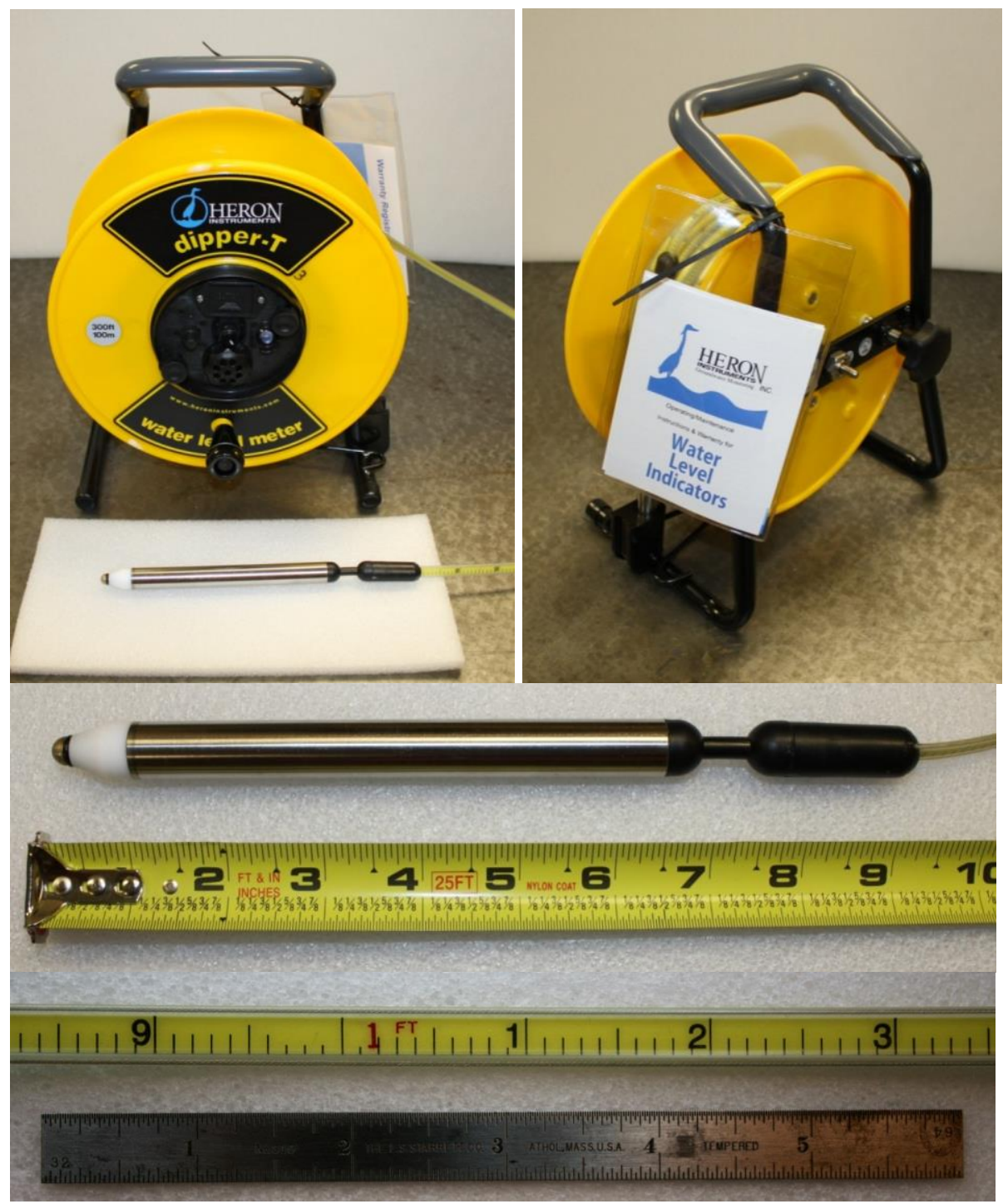

Figure 4. Heron dipper-T Water Level Meter: Photo of front of electric tape in upper left, photo of back of electric tape in upper right, closeup of probe in middle photo, and closeup of tape in bottom photo. 


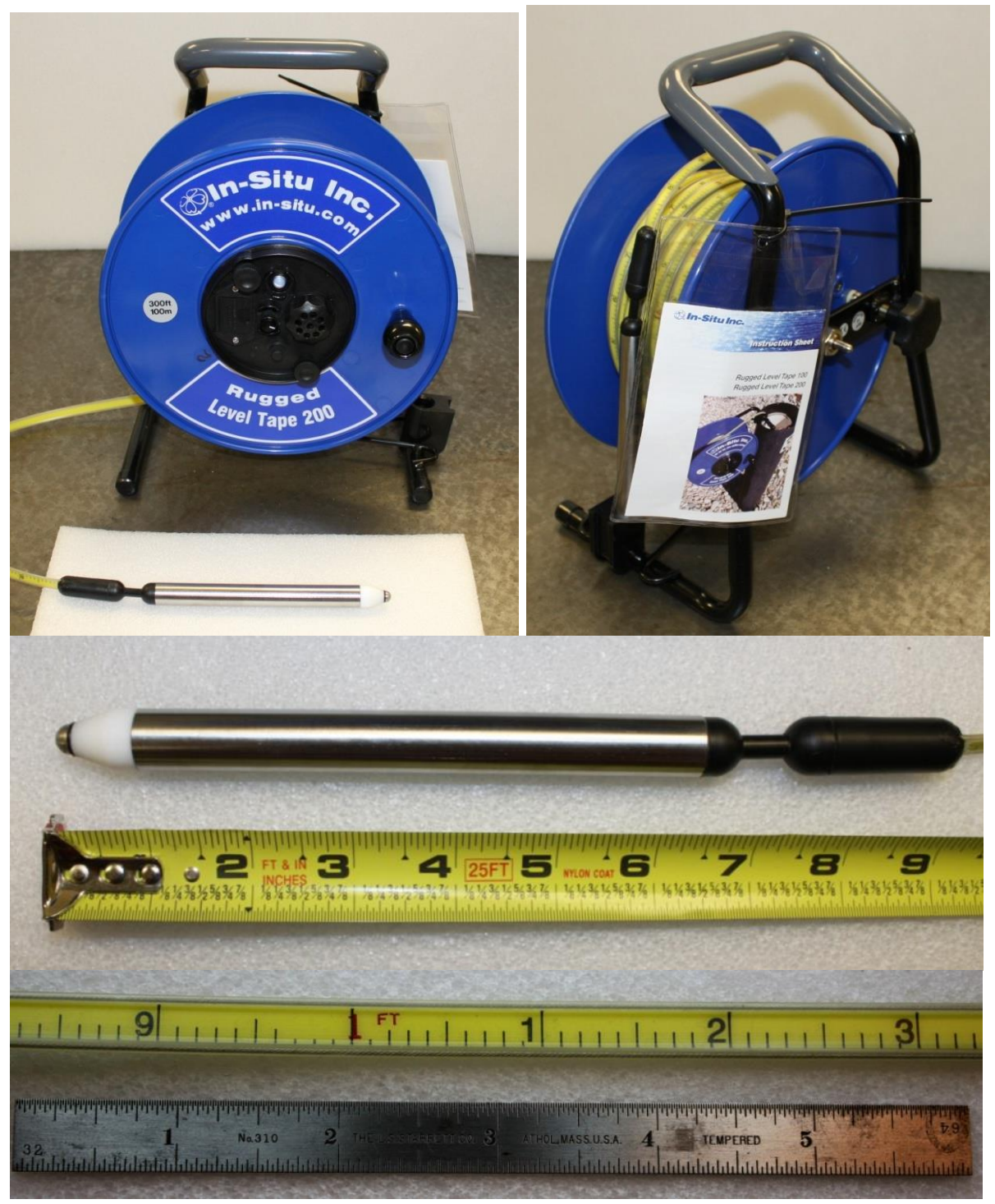

Figure 5. In-Situ Rugged Water Level Tape 200: Photo of front of electric tape in upper left, photo of back of electric tape in upper right, closeup of probe in middle photo, and closeup of tape in bottom photo. 


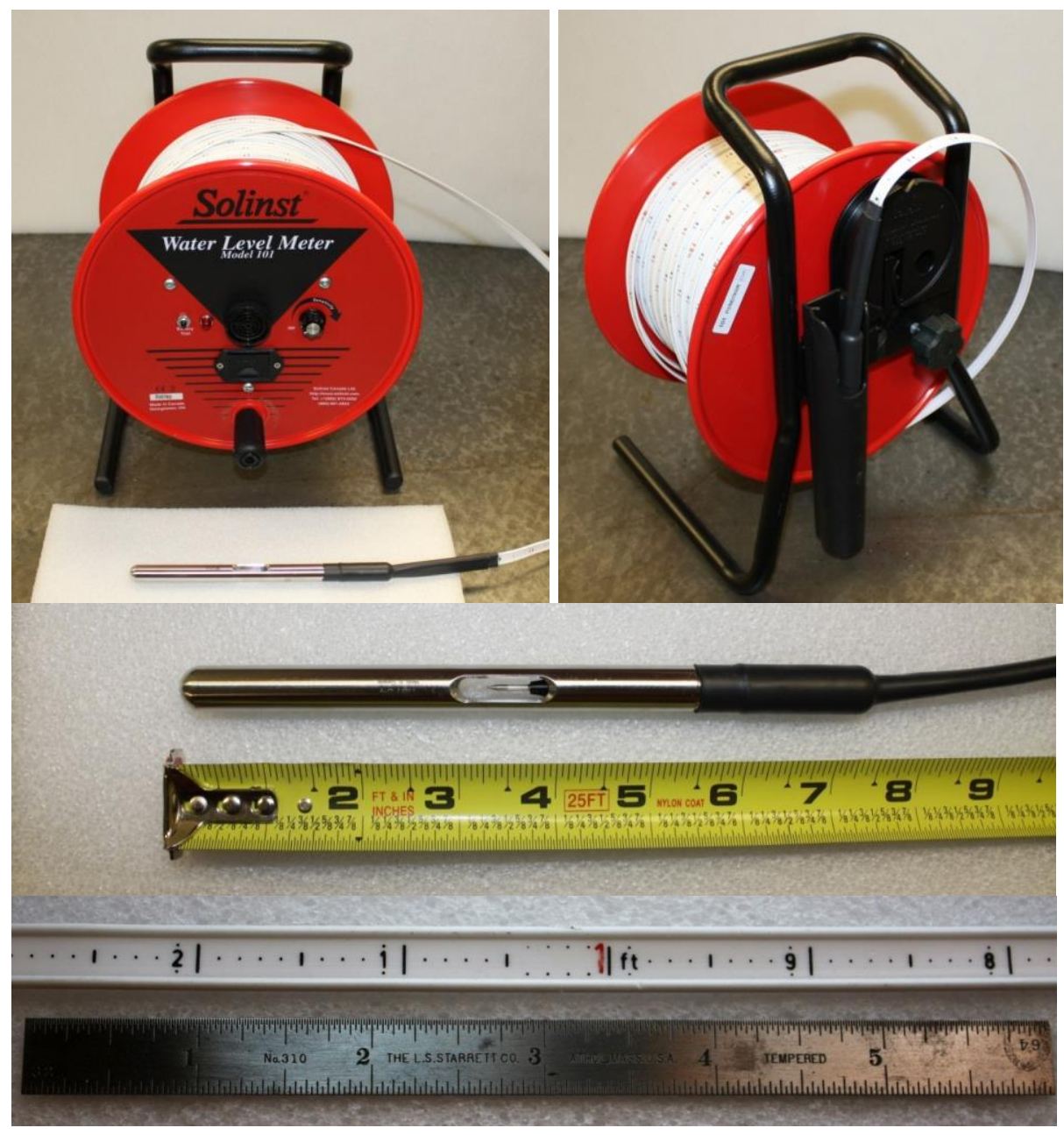

Figure 6. Solinst Model 101 P2 Water Level Meter: Photo of front of electric tape in upper left, photo of back of electric tape in upper right, closeup of probe in middle photo, and closeup of tape in bottom photo. 


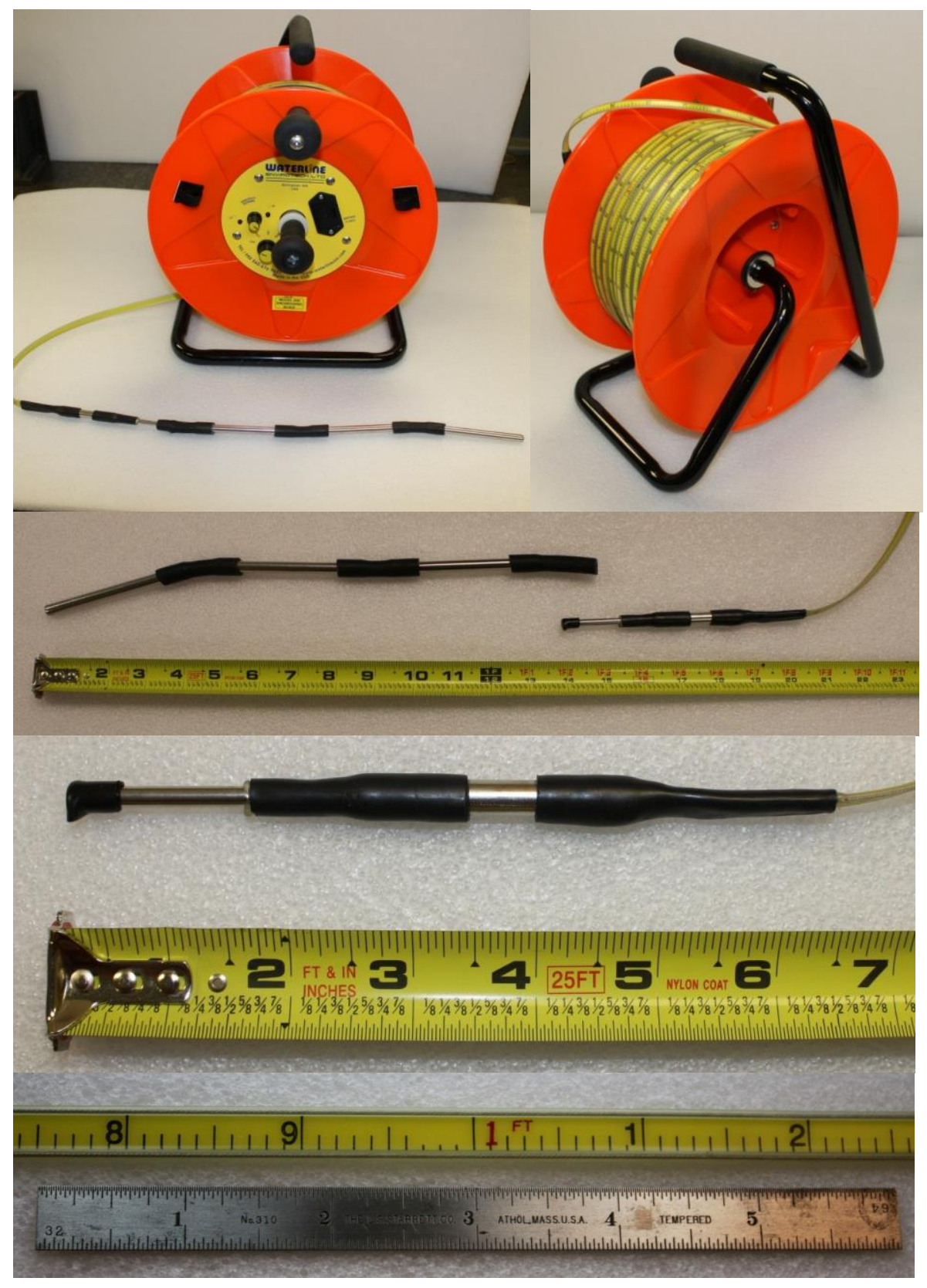

Figure 7. Waterline Model 500 Engineering Scale: Photo of front of electric tape in upper left, photo of back of electric tape in upper right, closeup of probe in middle photo, and closeup of tape in bottom photo. 

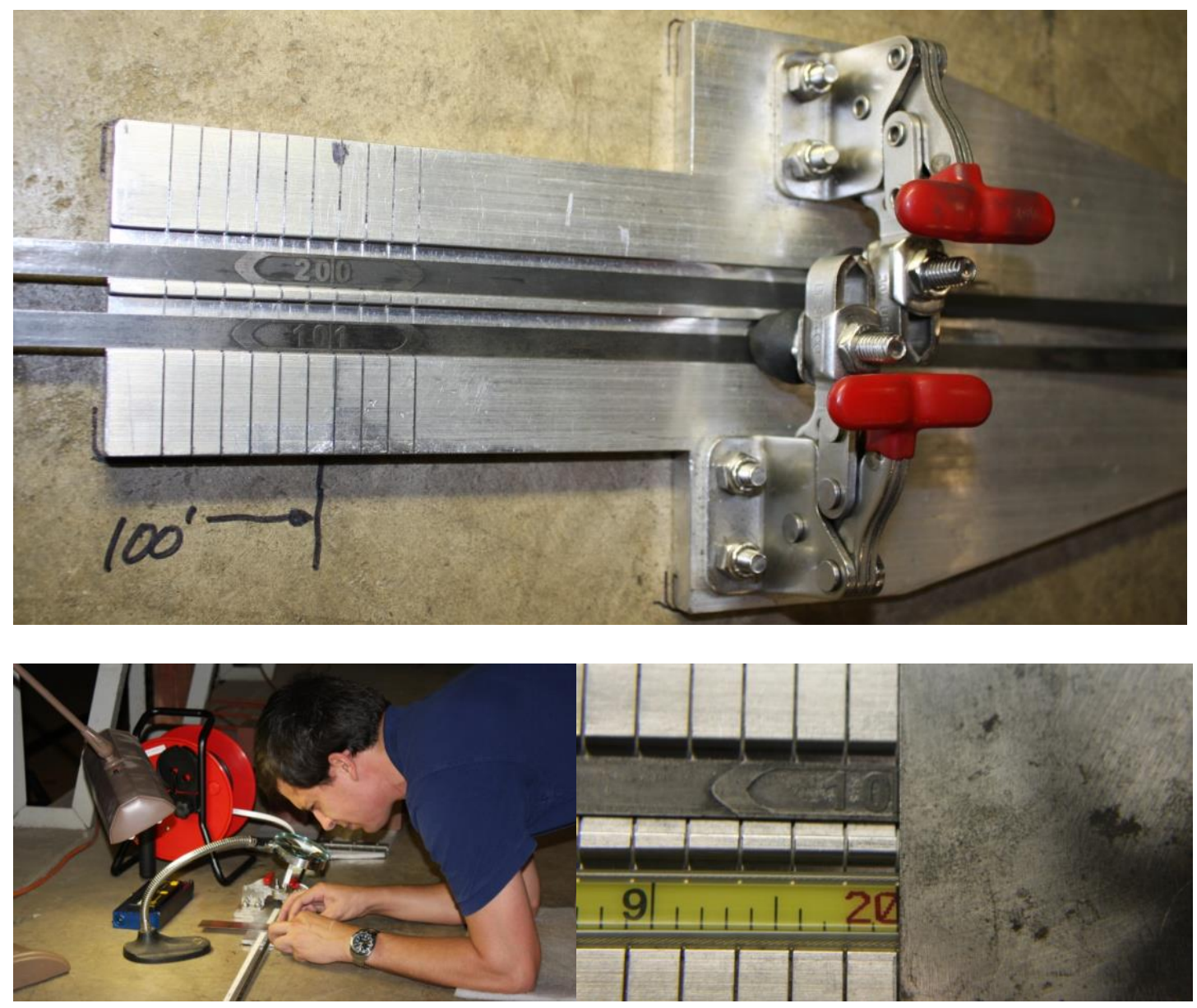

Figure 8. The anchor part of the tape length test apparatus. Upper photo: Two steel tapes in the apparatus. Lower left photo: aligning tape graduations in the apparatus. Lower right photo: Closeup of two tapes in the apparatus, and the blade of the machinist's square used to align them. 


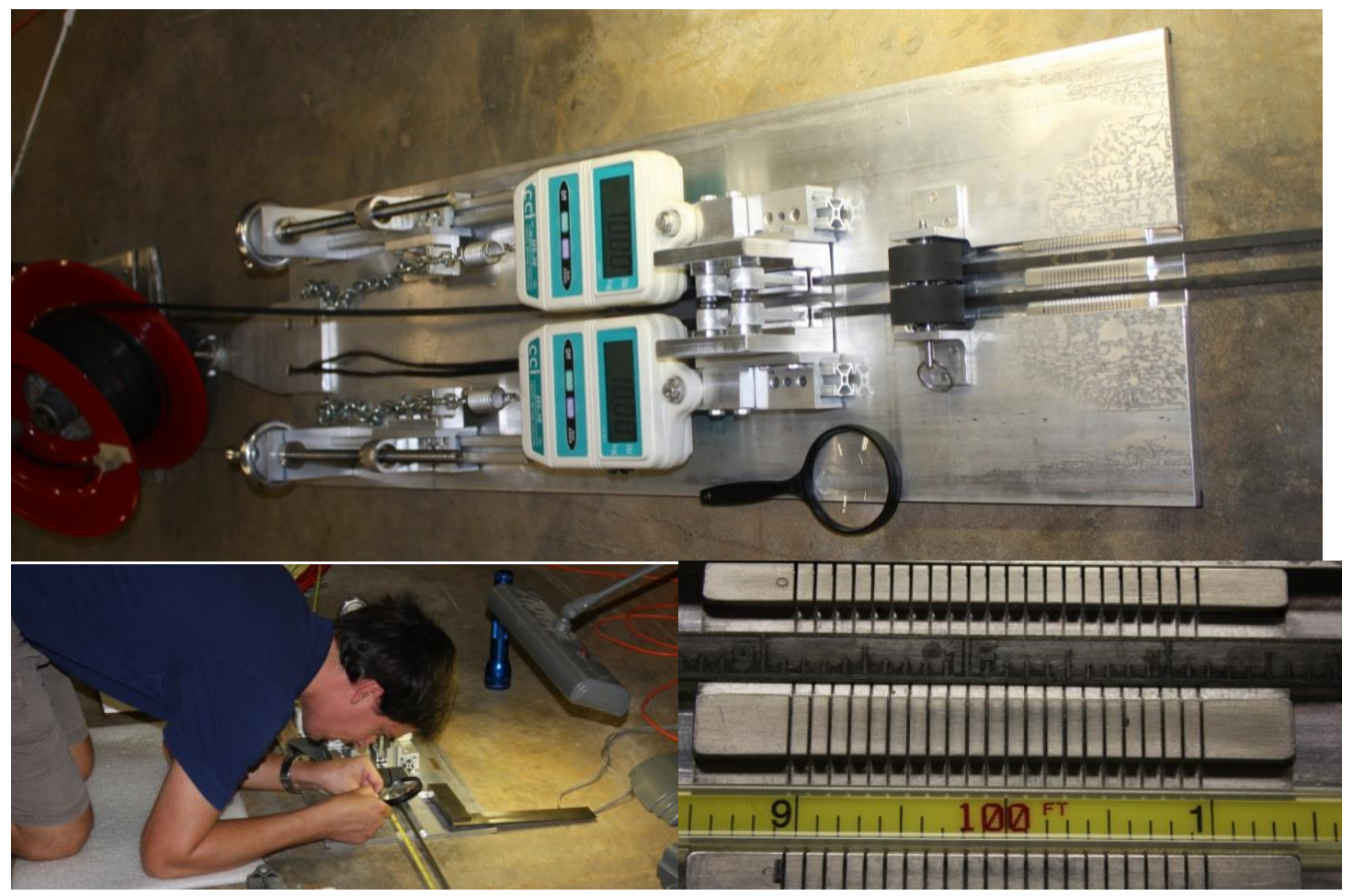

Figure 9. The tensioner part of the tape-length test apparatus. Upper photo: Two steel tapes in the apparatus attached to scales. Lower left photo: Tape graduations being compared using a magnifying glass and the Vernier scale. Lower right photo: Closeup of a steel tape (upper) and an electric tape (lower) on the Vernier scale. 

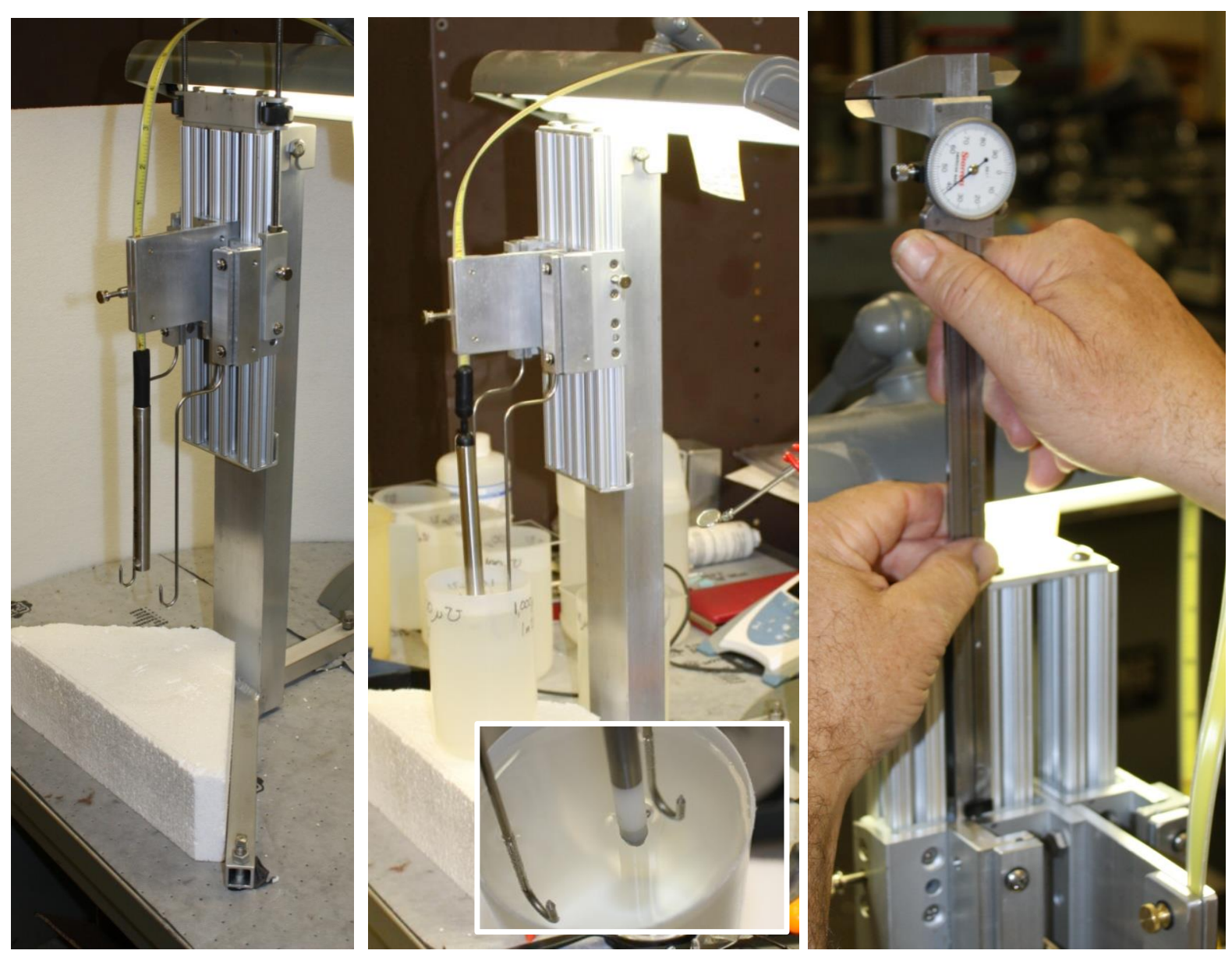

Figure 10. Three photos of probe-activation test apparatus. Left photo shows the apparatus with the water cup removed. Middle photo shows the apparatus with a tape installed and an inset photo of the hook gages at the water surface. Right photo shows measurement being made between two of the slide-assembly reference surfaces. 


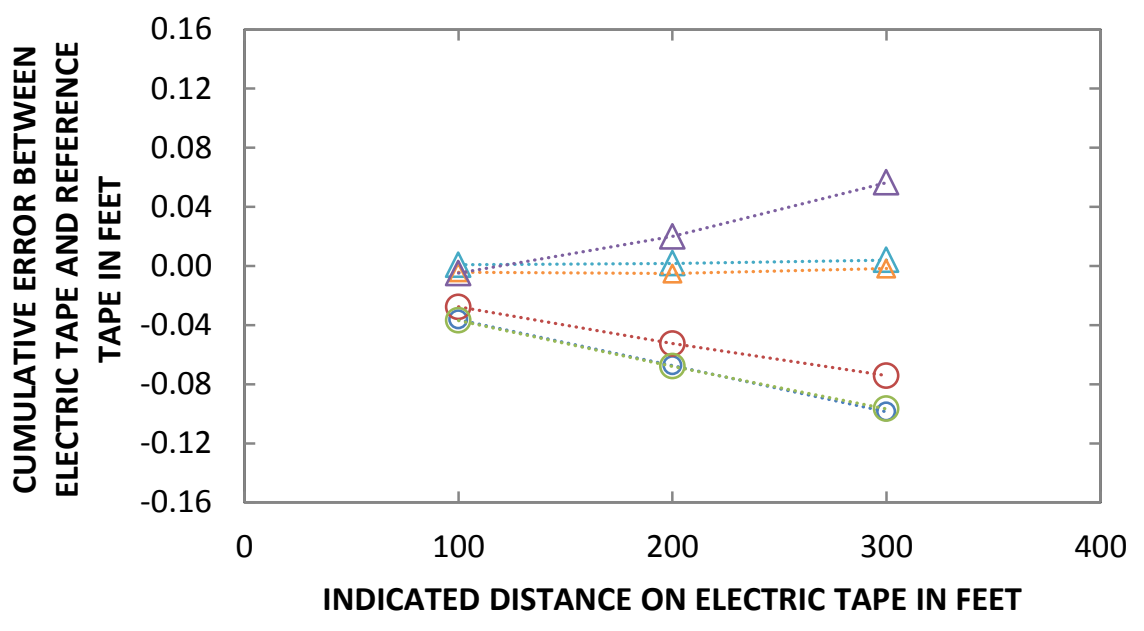

EXPLANATION

.......... In-Situ (sn 26330)

.......... In-Situ (sn 26331)

…...... In-Situ (sn 26332)

$\triangle$...... Solinst (sn 200806)

$\triangle \cdots \cdot$..... Solinst (sn 200808)

........ Solinst (sn 200793)

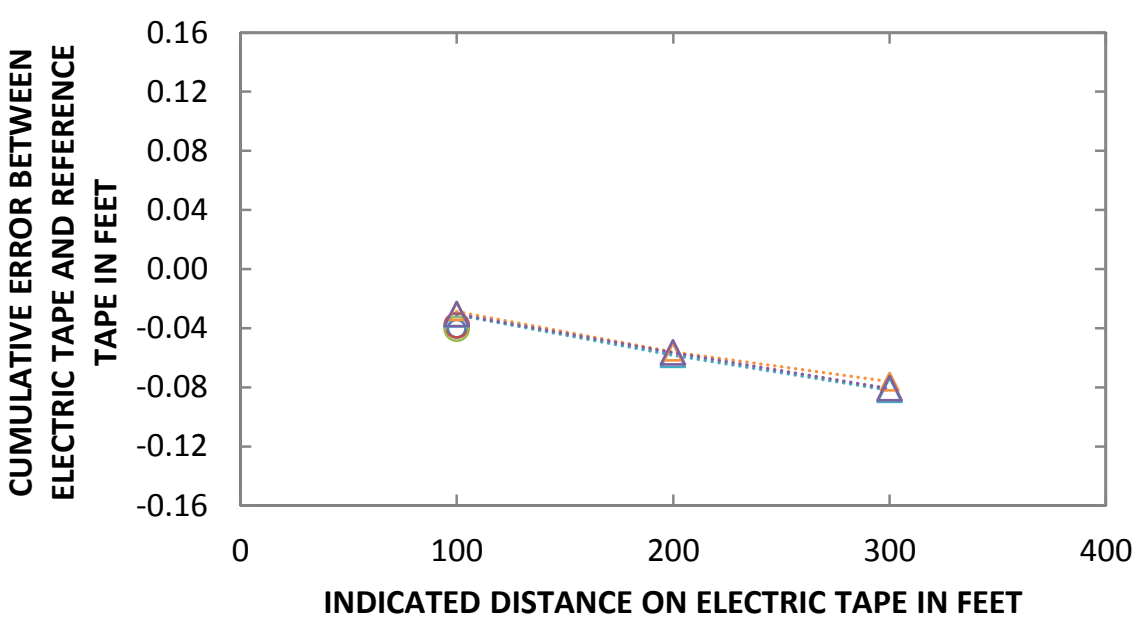

EXPLANATION

…...... Geotech (sn 4184)

......... Geotech (sn 4185)

…...... Geotech (sn 4189)

…..... Heron (sn 26328)

……. Heron (sn 26327)

……. Heron (sn 26329)

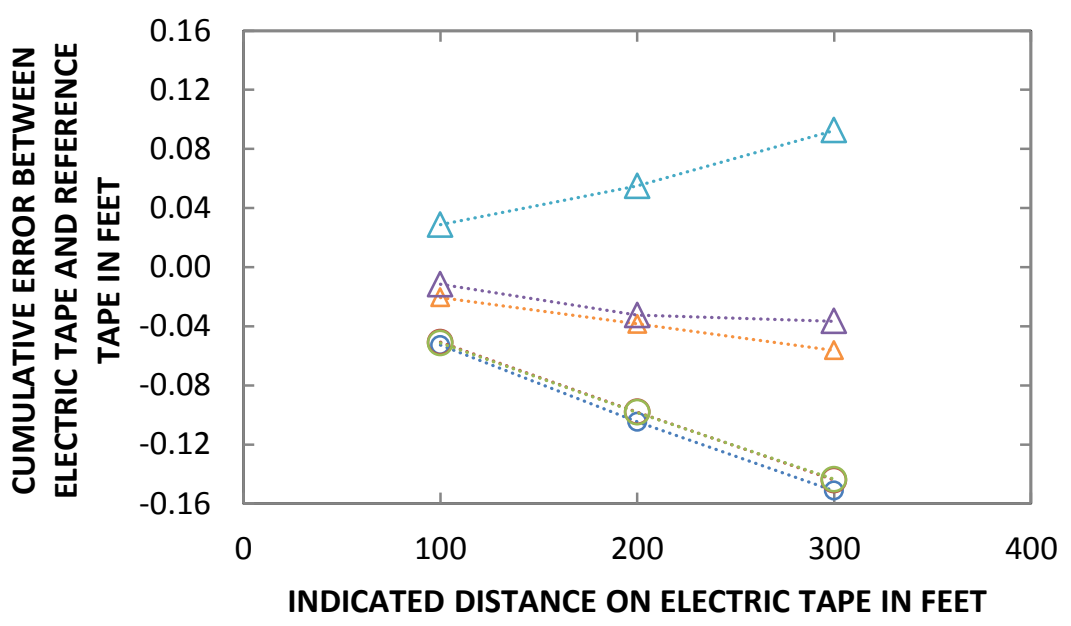

EXPLANATION

....... Waterline (sn 14671)

.......... Waterline (sn 14681)

....... Waterline (sn 00003)

...... Durham Geo (sn 29057)

…… Durham Geo (sn 29058)

A..... Durham Geo (sn 29056)

Figure 11. Cumulative error between 100-ft electric-tape segment and a steel reference tape over an electric-tape length of $300 \mathrm{ft}$. Electric tapes tested at their in-use tension and steel reference tape at its reference tension (sn=serial number). 


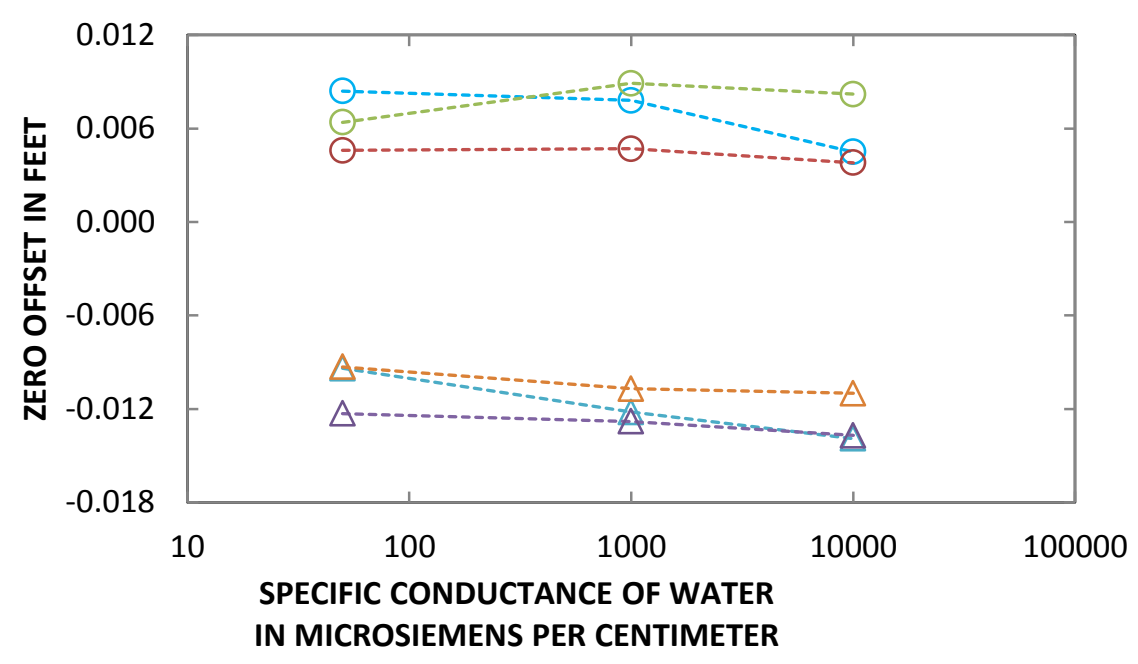

\section{EXPLANATION}

---@--- In-Situ (sn 26330)

---@--- In-Situ (sn 26331)

---๑-- In-Situ (sn 26332)

---A--- Solinst (sn 200806)

---A--- Solinst (sn 200793)

---A--- Solinst (sn 200808)

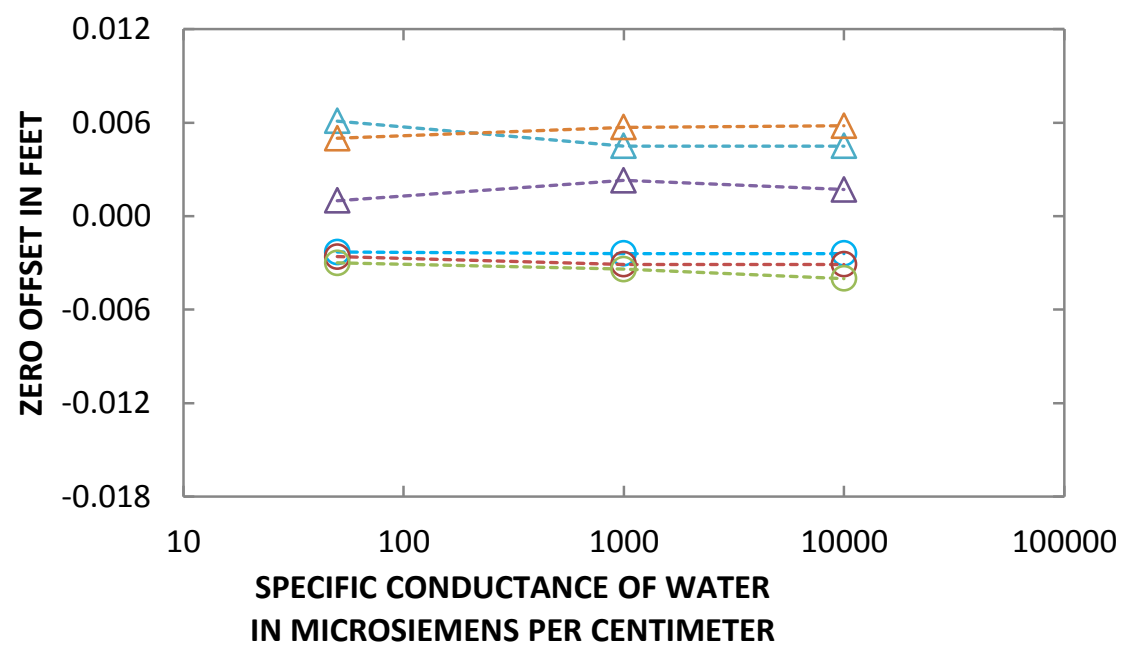

\section{EXPLANATION}

---๑-- Geotech (sn 4184)

---๑--- Geotech (sn 4185)

---९--- Geotech (sn 4189)

---A--- Heron (sn 26328)

---A--- Heron (sn 26329)

---A--- Heron (sn 26327)

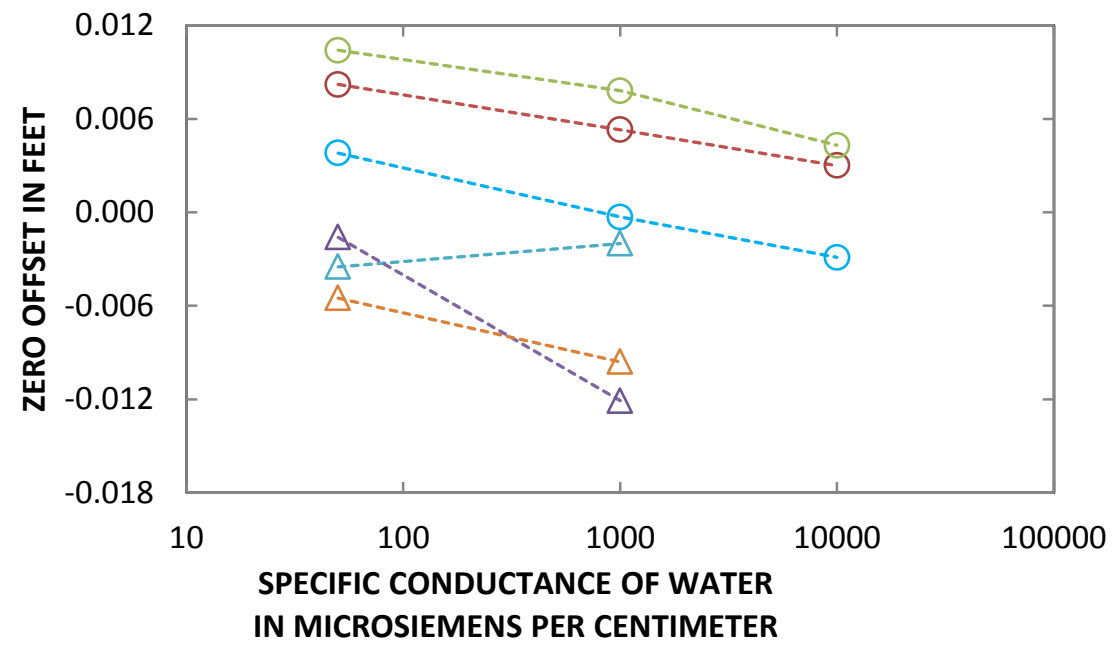

\section{EXPLANATION}

---@-- Waterline (sn 14671)

---@-- Waterline (sn 14681)

---๑-- Waterline (sn 00003)

---A--- Durham Geo (sn 29057)

---A--- Durham Geo (sn 29056)

---A--- Durham Geo (sn 29058)

Figure 12. Probe-activation zero offset in feet for water with various specific conductance values. Zero offset is positive for probes that activate lower and is negative for probes that activate higher than the zero end of the tape (sn=serial number). 

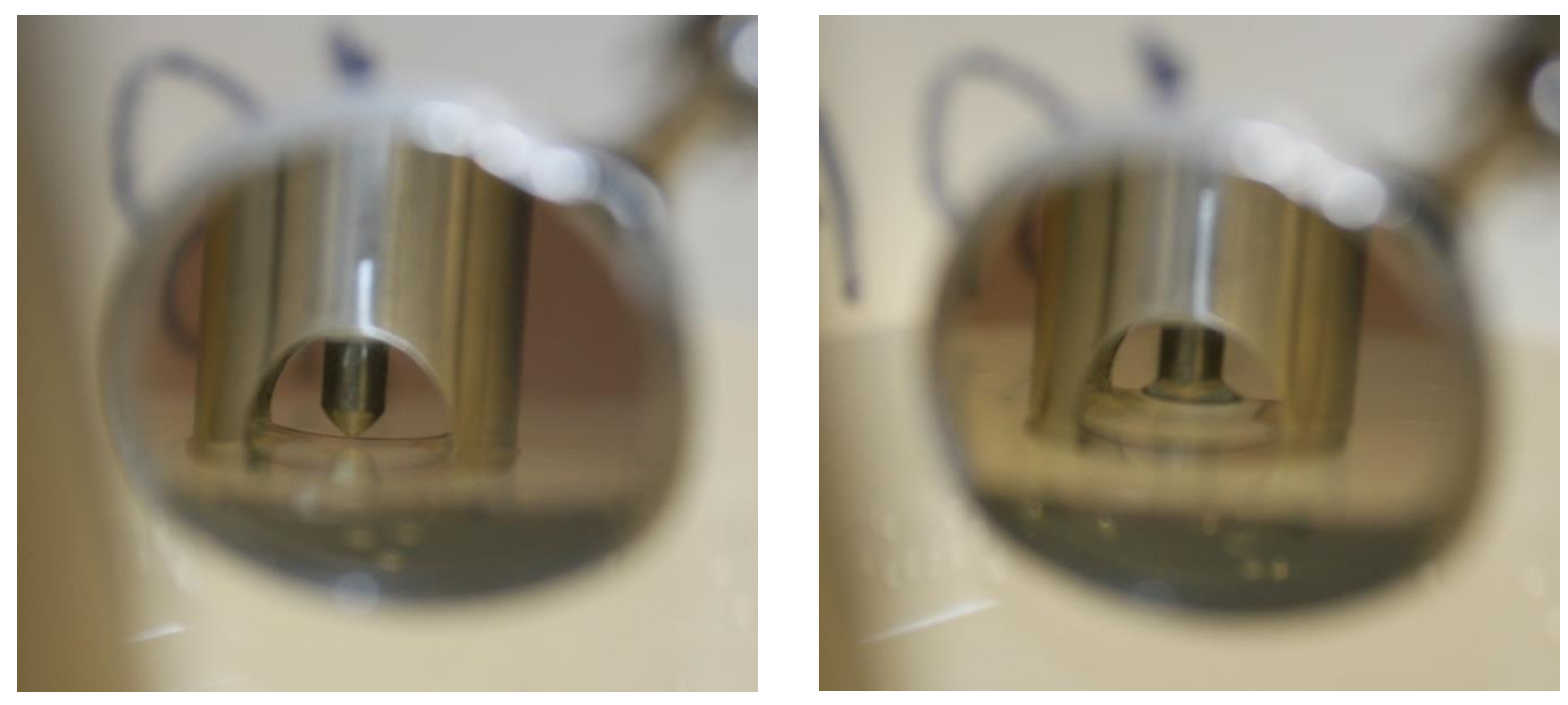

Figure 13. Closeup photos of the Geotech contact pin just at and after water contact. Note the small change in water height when the pin makes contact.
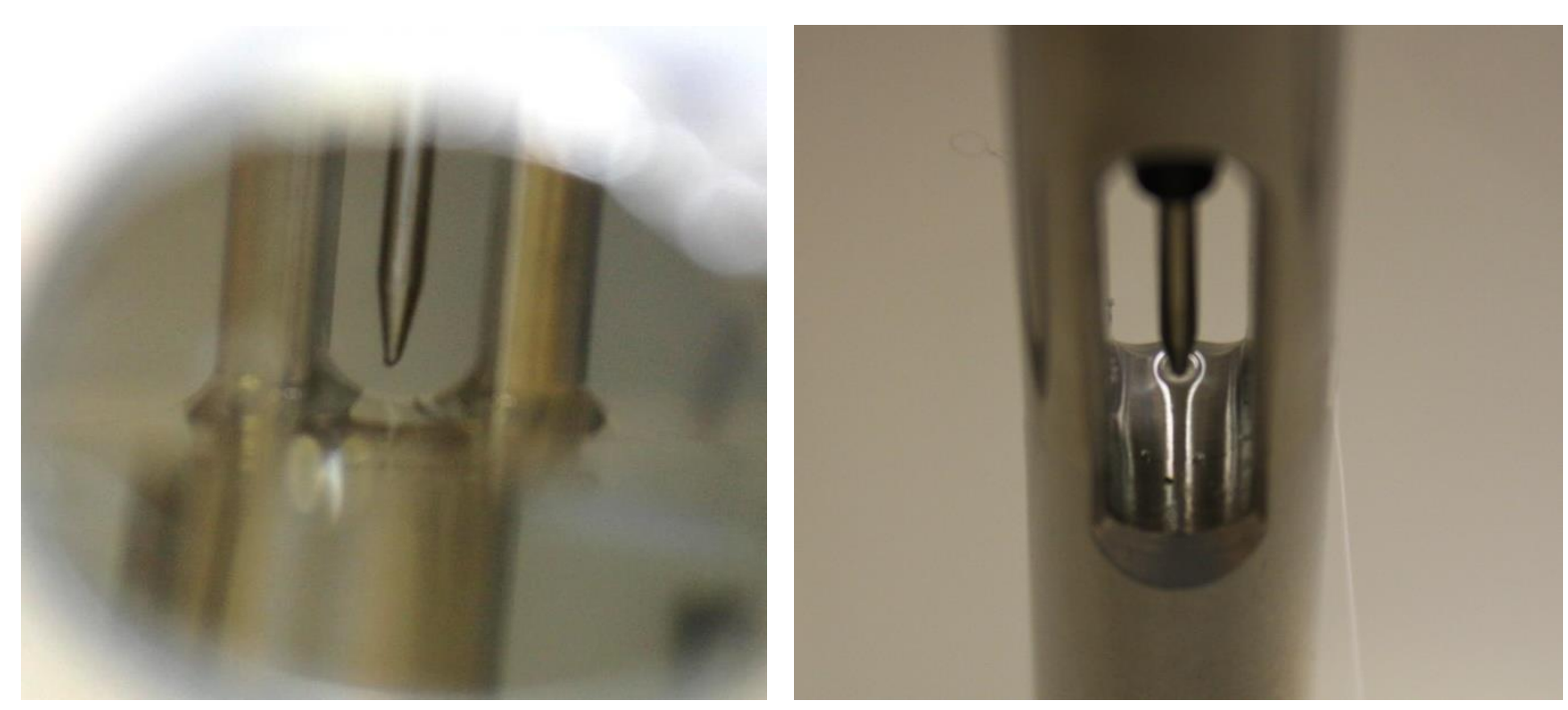

Figure 14. Closeup photos of the Solinst contact pin just before and just after water contact. Note the large change in water height when the pin makes contact. 


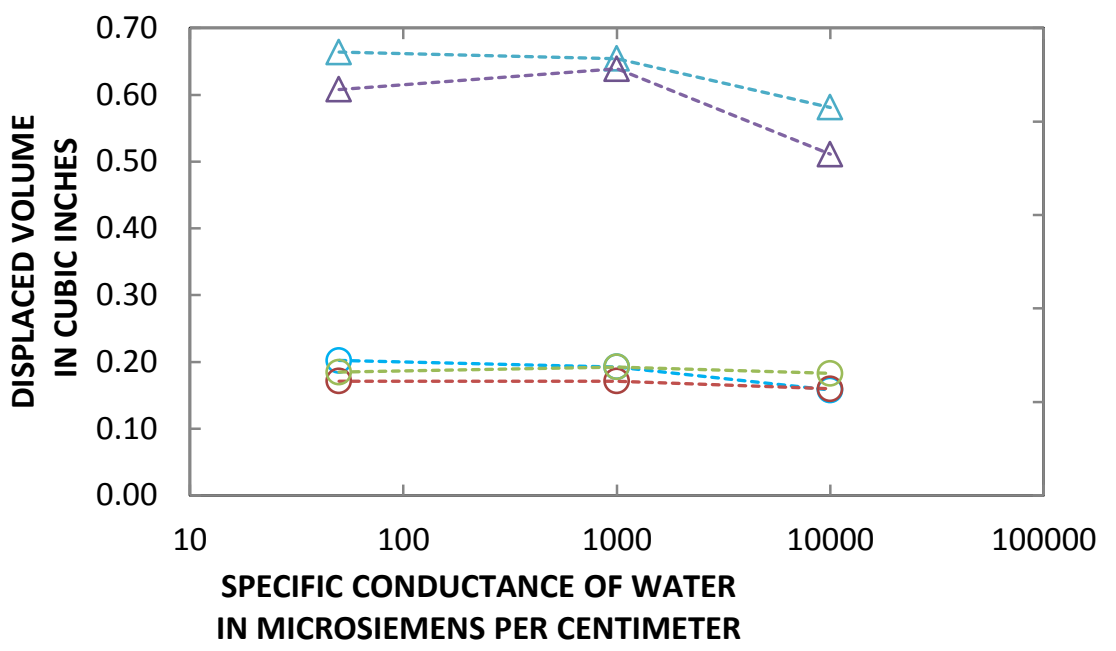

\section{EXPLANATION}

---๑-- In-Situ (sn 26330)

--๑--- In-Situ (sn 26331)

------ In-Situ (sn 26332)

---A--- Solinst (sn 200806)

---A--- Solinst (sn 200793)

---A--- Solinst (sn 200808)

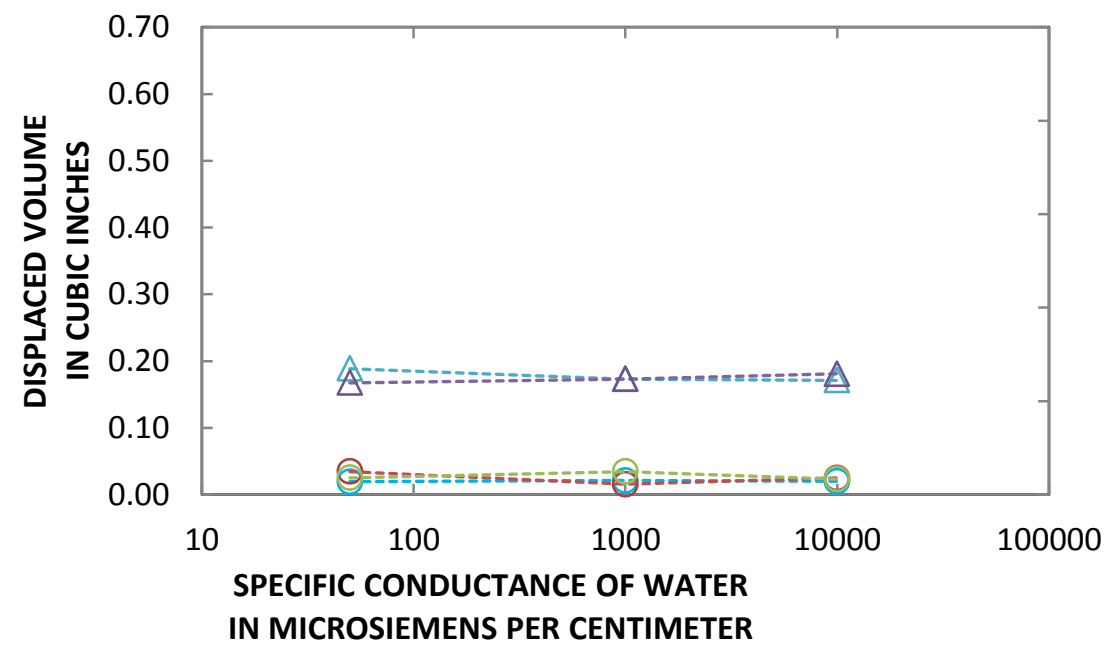

\section{EXPLANATION}

--- --- Geotech (sn 4184)

------ Geotech (sn 4185)

---९--- Geotech (sn 4189)

---A--- Heron (sn 26328)

---A--- Heron (sn 26329)

---A--- Heron (sn 26327)

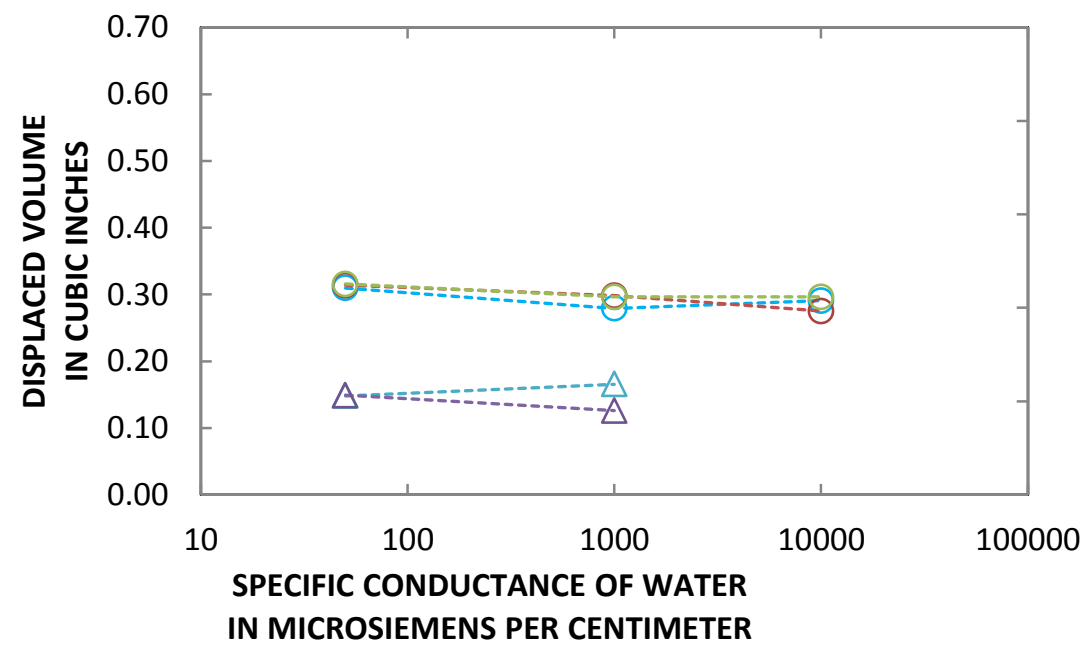

EXPLANATION

---@--- Waterline (sn 14671)

---๑-- Waterline (sn 14681)

------ Waterline (sn 00003)

---A--- Durham Geo (sn 29057)

---A--- Durham Geo (sn 29056)

---A--- Durham Geo (sn 29058)

Figure 15. The volume of water, in cubic inches, displaced by each probe when lowered to its activation point in water solutions with various specific conductance values (sn=serial number). 


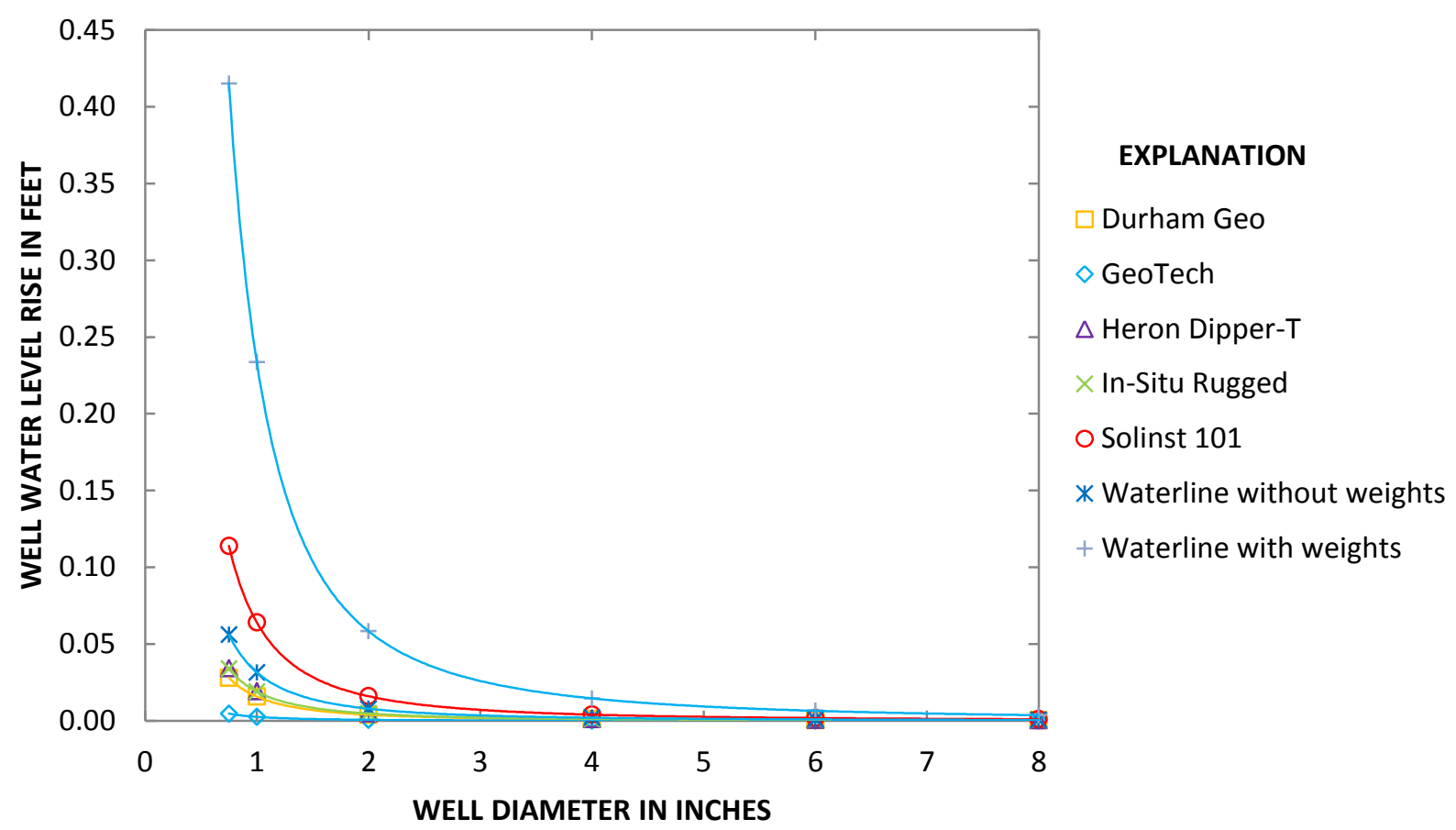

Figure 16. Well water-level rise with trend lines based on averaged probe-displacement volumes for six electric-tape models for averaged water sample specific conductance.

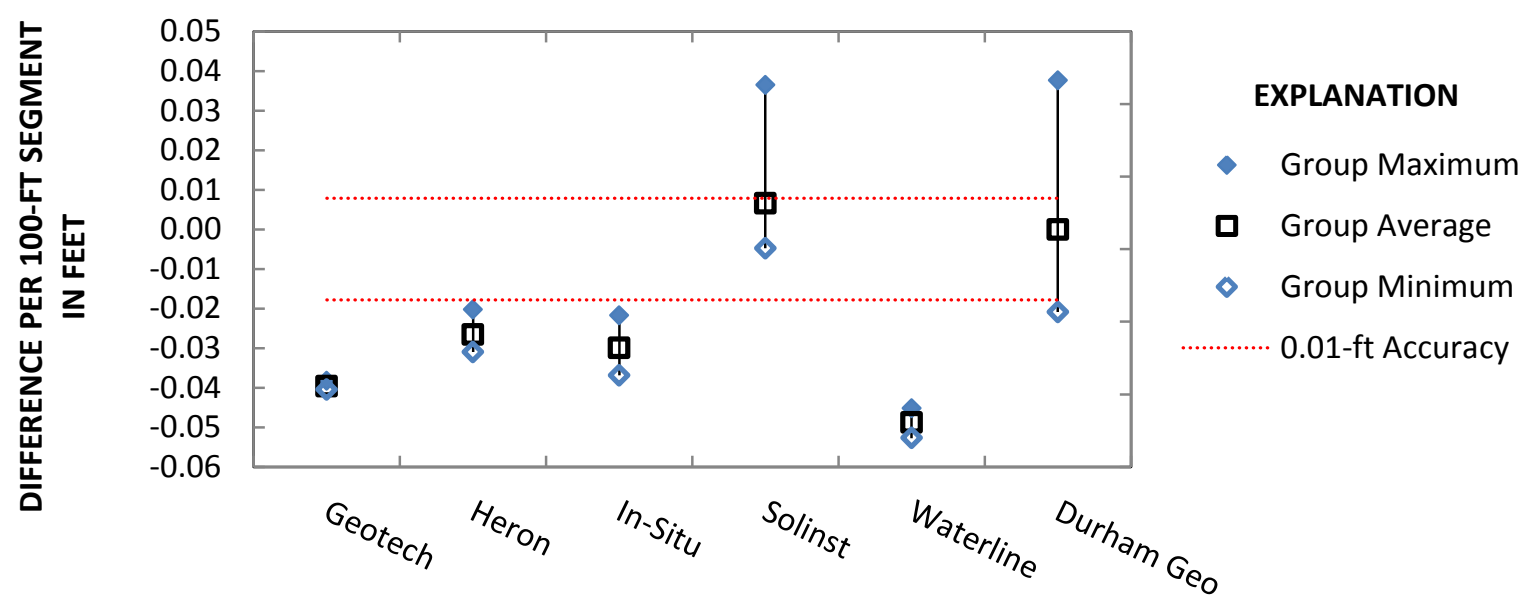

Figure 17. Model average, maximum, and minimum values for the tape-length accuracy for six different models of electric groundwater tape. 


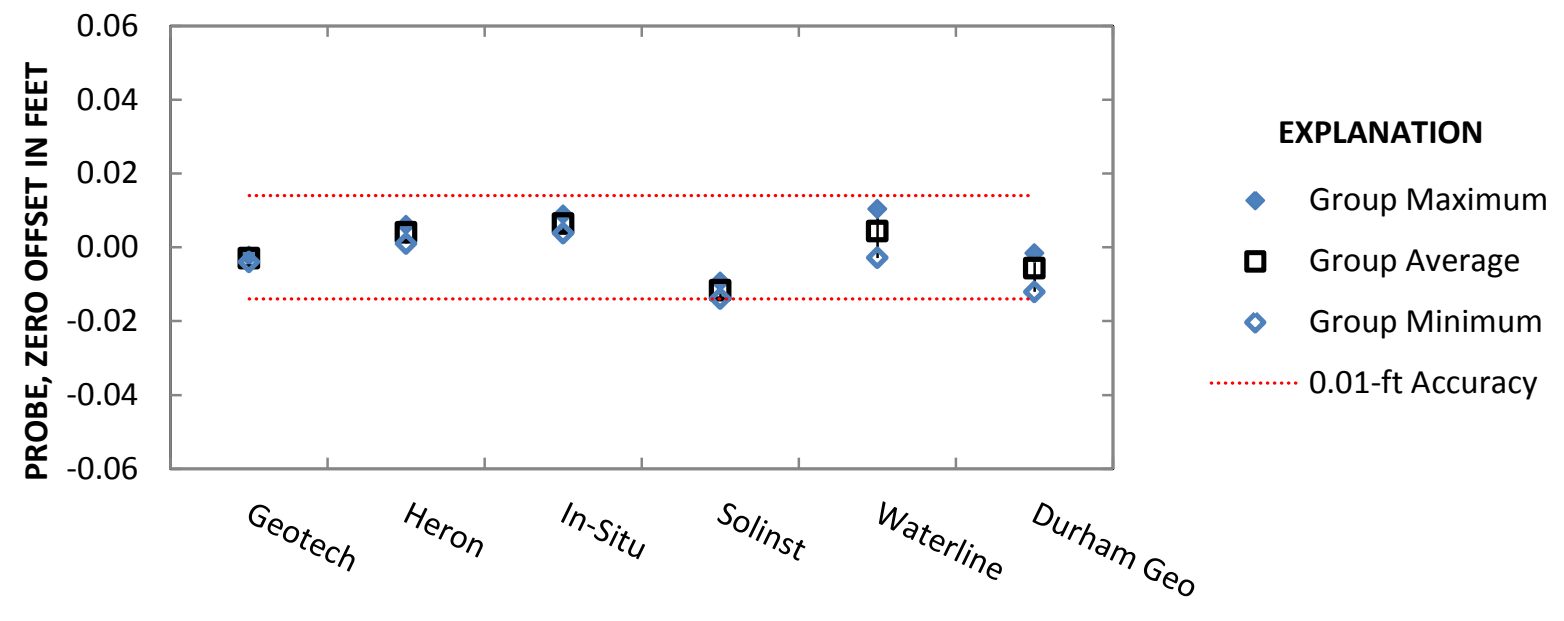

Figure 18. Model average, maximum, and minimum values for the zero offset for six different models of electric groundwater tape. 

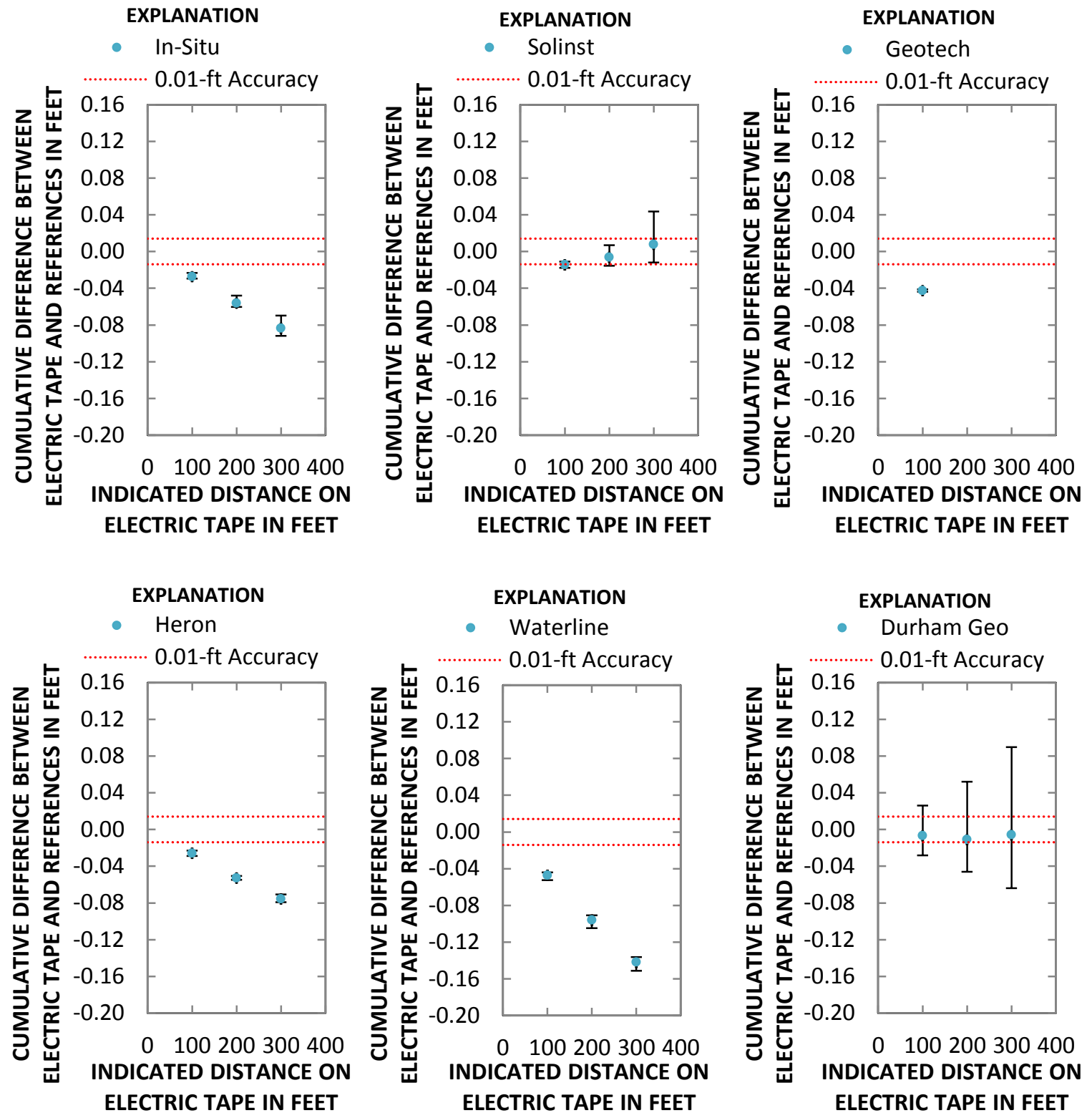

Figure 19. Cumulative average differences between electric-tape models and reference measurements over an electric-tape length of $300 \mathrm{ft}$ that include checks for tape-length accuracy and for probe zero offset. Three tapes per model are averaged. Electric tapes tested at its in-use tension. Error bars are the average difference for the tape with the maximum or minimum difference of the three model units tested. 
ISSN 2331-1258 (online) 